\title{
Intercomparison of desert dust optical depth from satellite measurements
}

\author{
E. Carboni ${ }^{1}$, G. E. Thomas ${ }^{1}$, A. M. Sayer ${ }^{1,2,11}$, R. Siddans $^{2}$, C. A. Poulsen $^{2}$, R. G. Grainger ${ }^{1}$, C. Ahn ${ }^{3}$, D. Antoine ${ }^{4}$, \\ S. Bevan $^{5}$, R. Braak ${ }^{6}$, H. Brindley ${ }^{7}$, S. DeSouza-Machado ${ }^{8}$, J. L. Deuzé ${ }^{9}$, D. Diner ${ }^{10}$, F. Ducos ${ }^{9}$, W. Grey ${ }^{5}$, C. Hsu ${ }^{11}$, \\ O. V. Kalashnikova ${ }^{10}$, R. Kahn ${ }^{11}$, P. R. J. North ${ }^{5}$, C. Salustro ${ }^{11, * *}$, A. Smith ${ }^{1}$, D. Tanré ${ }^{9}$, O. Torres ${ }^{11}$, and \\ B. Veihelmann ${ }^{6, *}$ \\ ${ }^{1}$ Atmospheric, Oceanic and Planetary Physics, Clarendon Laboratory, University of Oxford, Oxford, UK \\ ${ }^{2}$ Space Science and Technology Department, Rutherford Appleton Laboratory, Harwell Science and Innovation Campus, \\ Didcot, UK \\ ${ }^{3}$ Science Systems and Applications, Maryland, USA \\ ${ }^{4}$ Laboratoire d'Océanographie de Villefranche (LOV), Centre National de la Recherche Scientifique (CNRS) \\ and Université Pierre et Marie Curie, Paris 06, Villefranche-sur-Mer, France \\ ${ }^{5}$ Geography Department, College of Science, Swansea University, UK \\ ${ }^{6}$ Royal Netherlands Meteorological Institute (KNMI), The Netherlands \\ ${ }^{7}$ Imperial College, London, UK \\ ${ }^{8}$ University of Maryland Baltimore County, USA \\ ${ }^{9}$ LOA, Université Lille-1, France \\ ${ }^{10}$ Jet Propulsion Laboratory, California Institute of Technology, Pasadena, California, USA \\ ${ }^{11}$ NASA Goddard Space Flight Center, Greenbelt, Maryland, USA \\ *now at: Science, Applications and Future Technologies Department, ESA/ESTEC, The Netherlands \\ ** now at: Risk Management Solutions, Inc., Newark, California, USA \\ Correspondence to: E. Carboni (elisa@atm.ox.ac.uk)
}

Received: 30 November 2011 - Published in Atmos. Meas. Tech. Discuss.: 17 January 2012

Revised: 1 June 2012 - Accepted: 5 July 2012 - Published: 17 August 2012

\begin{abstract}
This work provides a comparison of satellite retrievals of Saharan desert dust aerosol optical depth (AOD) during a strong dust event through March 2006. In this event, a large dust plume was transported over desert, vegetated, and ocean surfaces. The aim is to identify the differences between current datasets. The satellite instruments considered are AATSR, AIRS, MERIS, MISR, MODIS, OMI, POLDER, and SEVIRI. An interesting aspect is that the different algorithms make use of different instrument characteristics to obtain retrievals over bright surfaces. These include multi-angle approaches (MISR, AATSR), polarisation measurements (POLDER), single-view approaches using solar wavelengths (OMI, MODIS), and the thermal infrared spectral region (SEVIRI, AIRS). Differences between instruments, together with the comparison of different retrieval algorithms applied to measurements from the same instru-
\end{abstract}

ment, provide a unique insight into the performance and characteristics of the various techniques employed. As well as the intercomparison between different satellite products, the AODs have also been compared to co-located AERONET data. Despite the fact that the agreement between satellite and AERONET AODs is reasonably good for all of the datasets, there are significant differences between them when compared to each other, especially over land. These differences are partially due to differences in the algorithms, such as assumptions about aerosol model and surface properties. However, in this comparison of spatially and temporally averaged data, it is important to note that differences in sampling, related to the actual footprint of each instrument on the heterogeneous aerosol field, cloud identification and the quality control flags of each dataset can be an important issue. 


\section{Introduction}

Desert dust is one of the most abundant and important aerosols in the atmosphere. Dust grain size and composition make it radiatively active over a wide spectral range (from the ultraviolet to the thermal infrared), and so airborne dust has a significant direct radiative forcing on climate (IPCC, 2007 ar4 2.4.1). Changes in land use can result in an anthropogenic influence on the atmospheric burden of desert dust. Dust can affect the atmospheric dynamics through its semi-direct radiative effect, and can modify precipitation by acting as ice nuclei. Iron transported by desert dust and deposited into the sea affects phytoplankton (Jickells et al., 2005).

Satellites can provide global measurements of desert dust and have particular importance in remote areas where there is a lack of in situ measurements. Desert dust sources are often in very poorly instrumented remote areas. Satellite aerosol retrievals have improved considerably in the last decade, and the number of related publications has correspondingly increased. However, intercomparison exercises (Myhre et al., 2005) have revealed that discrepancies between satellite measurements are particularly large during events of heavy aerosol loading.

In the past, aerosol retrievals for satellite radiometers have typically made use of visible and near-infrared measurements, the interpretation of which becomes difficult over bright surfaces such as deserts (Kaufman et al., 1997). To overcome these difficulties, more recent algorithms make use of additional information available from certain instruments, for example multi-angle observations, shorter (ultraviolet) wavelengths, thermal infrared wavelengths, and polarisation. All algorithms must also make prior assumptions about aerosol composition and the properties of the underlying surfaces, as the retrieval of aerosol properties is an inherently under-constrained optimisation problem. Instrumental observing capability and algorithm implementation (such as the use and formulation of prior information) give retrievals that are sensitive to different aspects of the dust aerosol loading. Using measurements from the same sensor, large variations in aerosol optical depth (AOD) can be found between different algorithms (Kokhanovsky et al., 2007) even in the idealised case of a non-reflecting surface (Kokhanovsky et al., 2010), or when only the assumed aerosol microphysical properties in a retrieval algorithm are changed (e.g. Bulgin et al., 2011).

In this paper, we report results from the Desert dust Retrieval Intercomparison (DRI) project, which performed a comparison of retrievals for a Saharan desert dust episode in March, 2006 using data from a wide range of state-ofthe-art schemes. This comparison reveals differences related to a range of factors including details of retrieval schemes, sensitivity of different instruments, accuracy of the aerosol model assumed, and the importance of good quality control. The aim of the study was to identify differences between the schemes, to highlight the strengths of particular schemes and help algorithm developers identify areas for further investigation.

The comparisons were performed separately over ocean (where satellite retrievals are less affected by problems in modelling the surface contribution to the top of atmosphere signal) and over land (where the retrieval problem is more challenging). The project also compiled a database of retrieval results which can be used in future work to test algorithm improvements.

\section{Datasets}

Most of the measurements considered here gave rise to more than a single estimate of AOD through the application of different retrieval algorithms. A pixel-by-pixel analysis of different algorithms applied to the same instrument or datasets from collocated pixels from different instruments, as MODIS and MISR (Mishchenko et al., 2010; Kahn et al., 2011), could lead to interesting results, but we leave this to future work. Here the comparison of satellite datasets is limited to the spatially and temporally averaged data. This enables results from a wide range of sensors to be compared, but somewhat complicates the interpretation of differences by introducing potentially large sampling effects.

The different spatial and temporal sampling available from different satellite instruments means that a direct comparison at the individual pixel (field-of-view) level is generally not possible. These differences in sampling can give differences in the retrieved AOD, particularly when the aerosol loading is spatially and/or temporally heterogeneous, or where cloud fields move between the overpasses of different sensors such that the cloud-free area imaged is not the same (e.g. Levy et al., 2009; Sayer et al., 2010b). The quality control in each individual retrieval algorithm may be different, so even retrievals from the same instrument will not necessarily have the same coverage. To minimise the effects of sampling differences on the intercomparison, data are aggregated to daily temporal resolution and a relatively fine spatial grid. To facilitate comparisons, each data provider has given two sets of results:

1. A daily AOD field formed by averaging individual retrievals onto a common spatial grid, namely a half degree regularly spaced grid in latitude and longitude. The mean AOD in each grid cell is provided along with the standard deviation of all individually retrieved AOD values in the cell and the number of these samples. These aggregated daily fields are directly compared (neglecting the fact that satellites may sample at different times of day). Most algorithms provide AOD near $550 \mathrm{~nm}$ with the exception of AIRS $\left(900 \mathrm{~cm}^{-1}\right.$ or $11 \mu \mathrm{m})$ and OMI-NASA $(440 \mathrm{~nm})$.

2. For comparison with ground-based direct-Sun observations from the Aerosol Robotic Network (AERONET; 
Holben et al., 1998), we use the mean and standard deviation of all individual retrievals within a radius of $50 \mathrm{~km}$ of selected AERONET sites, together with the number of individual retrievals and the mean observation time of those samples.

In the following text, the term "dataset" is used to refer to the AOD produced by the application of a named retrieval algorithm to measurements by a specific instrument. Comparisons are restricted to a region enclosed by latitudes 0 and $45^{\circ} \mathrm{N}$ and longitudes $50^{\circ} \mathrm{W}$ and $50^{\circ} \mathrm{E}$. Table 1 summarises the datasets included and a brief description of each dataset is provided below, organised by instrument.

The differences in using desert dust optical properties computed from spherical or non-spherical models can lead to significant effects (Mishchenko et al., 2003). In this comparison, the AATSR-ORAC, MISR, MODIS, POLDER-ocean, OMI-KNMI datasets include non-spherical optical models; the other datasets use only spherical models. This can lead to differences in retrieved AOD, especially for the datasets that make use of ultraviolet and visible wavelengths. Moreover, if dust is modelled assuming non-spherical particles, then additional decisions need to be made as to the specific distribution of particle shape(s) to use. These differences, which can be significant, will also affect the calculated phase function and so the retrieved AOD (e.g. Kalashnikova and Sokolik, 2002; Kalashnikova et al., 2005). These effects are not analysed in the present paper (due to the complexity added by multiangle retrievals), but for future research we suggest that an analysis of AOD differences between datasets as a function of scattering angle could help isolate phase function effects.

\subsection{AATSR}

\subsubsection{GlobAEROSOL}

The GlobAEROSOL project (http://www.atm.ox.ac.uk/ project/Globaerosol/) was carried out as part of the European Space Agency's Data User Element programme. All the products are on a common $10 \mathrm{~km}$ sinusoidal grid and together provide almost continuous coverage for 1995-2007. The instruments used by the project are the second Along Track Scanning Radiometer (ATSR-2), the Advanced ATSR (AATSR), the Medium Resolution Imaging Spectrometer (MERIS), and the Spinning Enhanced Visible Infrared Imager (SEVIRI).

The DRI intercomparison has made use of the AATSR GlobAEROSOL product derived using the OxfordRutherford Appleton Laboratory (RAL) Retrieval of Aerosol and Cloud (ORAC) optimal estimation scheme. A full description of the retrieval is given by Thomas et al. (2009). ORAC makes use of the ATSR nadir and forward view channels centred at $0.55,0.67,0.87$ and $1.6 \mu \mathrm{m}$. The forward model includes a bidirectional reflection distribution function (BRDF) description of the surface reflectance. By constraining the relative strengths of the direct, hemispher- ical and bi-hemispherical surface reflectance, the aerosol optical depth, effective radius (Reff) and bi-hemispherical surface albedo in each channel are retrieved. The a priori surface reflectance is determined by the MODIS BRDF product (MCD43B1 Collection 5.0) over land (Schaaf et al., 2002) and by an ocean surface reflectance model (Sayer et al., 2010a) over the ocean.

Retrievals are performed for each of five predefined aerosol types: desert dust, maritime clean, continental clean, urban (all using component optical properties from the Optical Properties of Aerosols and Clouds (OPAC) database of Hess et al., 1998) and biomass-burning (Dubovik et al., 2006). From these five results, a best match is selected based on the quality of the fit to the measurements and a priori constraints, providing a crude speciation of the aerosol.

Cloud screening is performed with the ESA operational cloud flag (Birks, 2004) and using the "opening test" (in addition to the usual quality control measures) to get rid of residual cloud, as documented in ESTEC (2006).

\subsubsection{ORAC}

The AATSR-ORAC dataset represents an updated version of the aerosol retrieval algorithm used in AATSRGlobAEROSOL. Three major aspects of the algorithm have been improved, described in detail by Lean (2009) and Sayer et al. (2012):

- Improved surface reflectance treatment. The error budget of the MODIS BRDF products used to generate the a priori surface albedo has been improved, and a correction algorithm applied to account for the differences between the visible channel spectral response functions of the MODIS and AATSR instruments.

- Implementation of aerosol type flags (volcanic ash, biomass burning over land, desert dust over sea) to identify aerosol pixels misclassified as cloudy by the supplied cloud flag.

- Development of a new aerosol microphysical model for desert dust. This uses the same refractive indices (derived from OPAC components) as in the AATSRGlobAEROSOL retrieval, but treats the particles as spheroids using T-matrix code (Mishchenko et al., 1997, 1998) rather than spheres. A modified log-normal distribution of spheroid aspect ratios (the ratio between major and minor axis length) as given by Sect. 3.4 of Kandler (2007) is used with equal numbers of oblate and prolate spheroids.

Cloud screening is performed with the ESA operational cloud flag (Birks, 2004).

\subsubsection{Swansea}

The Swansea University retrieval algorithm has been designed to retrieve the aerosol optical thickness and type, 
Table 1. List of the different datasets participating in the intercomparison, divided by instrument. The datasets are flagged with a cross for retrieval over land, over ocean and in comparison with AERONET sites.

\begin{tabular}{|c|c|c|c|c|}
\hline SEVIRI & Time UTC & Retrieval over: Ocean & Land & AERONET \\
\hline ORAC & $12: 12$ & $\mathrm{x}$ & $\mathrm{x}$ & $\mathrm{x}$ \\
\hline GlobAEROSOL & 10:00 13:00 16:00 & $\mathrm{x}$ & $\mathrm{x}$ & $\mathrm{x}$ \\
\hline Imperial VIS & $12: 12$ & $\mathrm{x}$ & & \\
\hline Imperial IR & $12: 12$ & & $\mathrm{x}$ & $\mathrm{x}$ \\
\hline AATSR & Orbit local time & & & \\
\hline ORAC & 10:00 & $\mathrm{x}$ & $\mathrm{x}$ & $\mathrm{x}$ \\
\hline GlobAEROSOL & $10: 00$ & $\mathrm{x}$ & $\mathrm{x}$ & $\mathrm{x}$ \\
\hline Swansea & $10: 00$ & $\mathrm{x}$ & $\mathrm{x}$ & $\mathrm{x}$ \\
\hline \multicolumn{5}{|l|}{ AIRS } \\
\hline JCET & $13: 30$ & $\mathrm{x}$ & $\mathrm{x}$ & \\
\hline \multicolumn{5}{|l|}{ OMI } \\
\hline NASA-GSFC & $13: 30$ & $\mathrm{x}$ & $\mathrm{x}$ & $\mathrm{x}$ \\
\hline KNMI & $13: 30$ & $\mathrm{x}$ & $\mathrm{x}$ & $\mathrm{x}$ \\
\hline \multicolumn{5}{|l|}{ MISR } \\
\hline JPL-GSFC & $10: 30$ & $\mathrm{x}$ & $\mathrm{x}$ & $\mathrm{x}$ \\
\hline \multicolumn{5}{|l|}{ MERIS } \\
\hline LOV & $10: 00$ & $\mathrm{x}$ & & $\mathrm{x}$ \\
\hline \multicolumn{5}{|l|}{ SEAWIFS } \\
\hline LOV & $12: 20$ & $\mathrm{x}$ & & $\mathrm{x}$ \\
\hline \multicolumn{5}{|l|}{ MODIS } \\
\hline NASA-GSFC & $10: 3013: 30$ & & $\mathrm{x}$ & $\mathrm{x}$ \\
\hline \multicolumn{5}{|l|}{ POLDER } \\
\hline Ocean & $13: 30$ & $\mathrm{x}$ & & $\mathrm{x}$ \\
\hline Land & $13: 30$ & & $\mathrm{x}$ & $\mathrm{x}$ \\
\hline
\end{tabular}

and surface reflectance over both land and ocean. The treatment of atmospheric radiative transfer is by look-up table (LUT) using the scalar version of $6 \mathrm{~S}$ code (Vermote et al., 1997; Grey et al., 2006a). Five aerosol models are represented: two coarse modes (oceanic, desert) and three fine mode (biomass burning, continental and urban). The optimum value of AOD and aerosol model is selected by iterative inversion based on fit to a model of surface reflectance. Over ocean, the algorithm uses the low spectral reflectivity at near and mid-infrared channels to constrain aerosol retrieval (Grey et al., 2006b; Bevan et al., 2012). Over land, the algorithm uses the AATSR dual-view capability to estimate aerosol without prior assumptions of land surface spectral properties, based on inversion of a simple parametrized model of surface anisotropy (North et al., 1999; North, 2002; Davies et al., 2010). This model defines spectral variation of reflectance anisotropy accounting for variation in diffuse light from the atmosphere and multiple scattering at the surface. Cloud clearing is based on instrument flags enhanced by the cloud detection system developed by Plummer (2008).
The retrieval procedure was implemented within ESA's Grid Processing on Demand (GPOD), high-performance computing facility for global retrievals of AOD and bidirectional reflectance from ATSR-2 and AATSR, at $10 \mathrm{~km}$ resolution, and these data are used in the current study. Global validation with AERONET and other satellite sensors was presented by Grey et al. (2006b) and Bevan et al. (2012). Bevan et al. (2009) performed validation of GPOD ATSR-2 and explored the impact of atmospheric aerosol from biomass burning in the Amazon region over the full 13yr ATSR-2/AATSR dataset. Further details on the algorithm are given in Grey and North (2009).

\subsection{AIRS}

\subsubsection{JCET}

Operational since September 2002, the Atmospheric Infrared Sounder (AIRS) instrument (Aumann et al., 2003) on NASA's Aqua satellite provides data for temperature and humidity profiles, used in numerical weather prediction. AIRS has 2378 channels, covering the spectral range 649-1136, 
1217-1613, 2181-2665 $\mathrm{cm}^{-1}$. Each cross track swath consists of 90 pixels, with a footprint of $15 \mathrm{~km}$ at nadir.

Upwelling radiances in the $8-12 \mu \mathrm{m}$ thermal infrared (TIR) atmospheric window are measured with a large number of high-resolution, low noise channels, making it possible to detect silicate-based aerosols (De Souza-Machado et al., 2006, 2010) day or night, over ocean or land. A dust detection algorithm has been developed using brightness temperature differences (BTDs) for a set of 5 AIRS channels in the TIR region. The algorithm is based on simulations of dustcontaminated radiances for numerous atmospheric profiles over ocean using dust refractive indices from Volz (1973). This flag was designed to detect dust over tropical and mid latitude oceans (which have no cloud cover over the dust), and can be modified to work over land surfaces.

The retrieval uses a modified version of the AIRS Radiative Transfer Algorithm (AIRS-RTA), which computes radiative transfer through a dusty atmosphere (Chou et al., 1999). The AIRS-RTA assumes a plane parallel atmosphere divided into 100 layers, with the dust profile occupying one or more consecutive pressure layers.

The algorithm assumes knowledge of the effective particle size and dust top/bottom height. Here an effective particle diameter of $4 \mu \mathrm{m}$ for a log-normal distribution is adopted. The dust height comes from GOCART climatology (Ginoux et al., 2001). Given this, a linearised Newton-Raphson method fits for the column dust loading $\Gamma$ (in $\mathrm{g} \mathrm{m}^{2}$ ) to minimise a $\chi^{2}$ least square fit of brightness temperatures (BTs) in the window regions. The dust loading is related to the TIR dust AOD $\tau$ by

$\tau(v)=\sigma_{\text {dust model }}\left(v, r_{\text {mode }}\right) \Gamma$.

Here $\sigma_{\text {dust model }}\left(v, r_{\text {mode }}\right)$ is the mass extinction efficiency in $\mathrm{m}^{2} \mathrm{~g}^{-1}$. It is important to note that the retrieved TIR AOD depends critically on the assumed particle height. Comparisons show that, when the heights are correct, AIRS AODs have a very high correlation against MODIS and POLDER AODs, especially over the ocean (De Souza-Machado et al., 2010). This correlation drops noticeably when the heights are incorrect.

\subsection{OMI}

\subsubsection{NASA-GSFC}

The first step in the OMAERUV algorithm is the calculation of the UV Aerosol Index (UVAI) as described in Torres et al. (2007). The information content of the OMI UVAI is turned into quantitative estimates of aerosol extinction optical depth and single scattering albedo (SSA) at $388 \mathrm{~nm}$ by application of an inversion algorithm to OMI near-UV observations at 354 and $388 \mathrm{~nm}$ (Torres et al., 2007). These aerosol parameters are derived by an inversion algorithm that uses pre-calculated reflectances for a set of assumed aerosol models. A climatological dataset of near-UV surface albedo derived from long-term TOMS (Total Ozone Mapping Spectrometer) observations is used to characterise surface reflective properties. Three major aerosol types are considered: desert dust, carbonaceous aerosols associated with biomass burning, and weakly absorbing sulfate-based aerosols. The selection of an aerosol type makes use of a combination of spectral and geographic considerations (Torres et al., 2007). The aerosol model particle size distributions were derived from long-term AERONET statistics (Torres et al., 2007).

Since the retrieval procedure is sensitive to aerosol vertical distribution, the aerosol layer height is assumed based on aerosol type and geographic location. Carbonaceous aerosol layers within $30^{\circ} \mathrm{N}$ of the Equator are assumed to have a maximum concentration $3 \mathrm{~km}$ above ground level, whereas mid and high-latitude (polewards of $45^{\circ} \mathrm{N}$ ) smoke layers are assumed to peak at $6 \mathrm{~km}$. The height of smoke layers between $30^{\circ}$ and $45^{\circ}$ latitude in both hemispheres is interpolated with latitude between 3 and $6 \mathrm{~km}$. The location of desert dust aerosol layers varies between 1.5 and $10 \mathrm{~km}$, and is given by a multi-year climatological average of chemical model transport calculations using the GOCART model at a lat-long resolution of $2^{\circ} \times 2.5^{\circ}$ (Ginoux et al., 2001). For sulfate-based aerosols, the assumed vertical distribution is largest at the surface and decreases exponentially with height.

For a chosen aerosol type and assumed aerosol layer height, the extinction optical depth and single scattering albedo at $388 \mathrm{~nm}$ are retrieved and aerosol absorption optical depth is calculated. Results are also reported at 354 and $500 \mathrm{~nm}$ to facilitate comparisons with measurements from other space-borne and ground-based sensors.

Aerosol parameters over land are retrieved for all cloudfree scenes as determined by an internal cloud mask. Retrievals over the ocean, however, are limited to cloud-free scenes containing absorbing aerosols (i.e. smoke or desert dust) as indicated by UVAI values larger than unity. Since the current representation of ocean surface effects in the OMAERUV algorithm does not explicitly correct for ocean colour signal, the retrieval of accurate background maritime aerosol is not currently possible.

Algorithm quality flags are assigned to each pixel. Most reliable OMAERUV retrievals have a quality flag 0 . Quality flag 1 indicates sub-pixel cloud contamination. For quantitative applications using OMAERUV-derived aerosol optical depth and single scattering albedo, only data of quality flag 0 are recommended. For this comparison flag 0 , data have been extrapolated to $440 \mathrm{~nm}$.

\subsubsection{KNMI}

The OMI multi-wavelength algorithm OMAERO (Torres et al., 2002) is used to derive aerosol characteristics from OMI spectral reflectance measurements of cloud-free scenes. Under cloud-free conditions, OMI reflectance measurements are sensitive to the aerosol optical depth, the single scattering albedo, the size distribution, altitude of the aerosol layer, 
and the reflective properties of the surface. However, from a principal-component analysis applied to synthetic reflectance data (Veihelmann et al., 2007), it was shown that OMI spectra contain only two to four degrees of freedom of signal. Hence, OMI spectral reflectance measurements do not contain sufficient information to retrieve all aerosol parameters independently. The OMAERO level-2 data product reports aerosol characteristics such as the AOD, aerosol type, aerosol absorption indices as well as ancillary information. The AOD is retrieved from OMI spectral reflectance measurements, and a best-fitting aerosol type is determined. The single scattering albedo, the layer altitude and the size distribution associated with the best-fitting aerosol type are reported.

Cloudy scenes are excluded from the retrieval using three tests. The first test is based on reflectance data in combination with the UV absorbing aerosol index. The second test uses cloud fraction data from the OMI O2-O2 cloud product OMCLDO2 (Acarreta and Hann, 2002; Acarreta et al., 2004; Sneep et al., 2008). The third test is based on the spatial homogeneity of the scene. The latter test is the most strict for screening clouds in the current implementation of the algorithm.

The OMAERO algorithm evaluates the OMI reflectance spectrum in a set of 15 wavelength bands in the spectral range between 330 and $500 \mathrm{~nm}$. The wavelength bands are about $1 \mathrm{~nm}$ wide and were chosen such that they are essentially free from gas absorption and strong Raman scattering features, except for a band at $477 \mathrm{~nm}$, which comprises an $\mathrm{O} 2-\mathrm{O} 2$ absorption feature. The sensitivity to the layer altitude and single scattering albedo is related to the relatively strong contribution of Rayleigh scattering to the measured reflectance in the UV (Torres et al., 1998). The absorption band of the $\mathrm{O} 2-\mathrm{O} 2$ collision complex at $477 \mathrm{~nm}$ is used in OMAERO to enhance the sensitivity to the aerosol layer altitude (Veihelmann et al., 2007).

The multi-wavelength algorithm uses forward calculations for a number of microphysical aerosol models that are defined by the size distribution and the complex refractive index, as well as the AOD and the aerosol layer altitude. The models are representative for the main aerosol types of desert dust, biomass burning, volcanic and weakly absorbing aerosol. Several sub-types or models represent each of these main types. Synthetic reflectance data have been precomputed for each aerosol model using the Doubling-Adding KNMI program (De Haan et al., 1987; Stammes et al., 1989; Stammes, 2001), assuming a plane-parallel atmosphere and taking into account multiple scattering as well as polarisation. For land scenes, the surface albedo spectrum is taken from a global climatology that has been constructed using Multi-angle Imaging Spectroradiometer (MISR) data measured in four bands (at 446, 558, 672, and $866 \mathrm{~nm}$ ) that are extrapolated to the UV. For ocean surfaces, the spectral bidirectional reflectance distribution function is computed using a model that accounts for the chlorophyll concentration of the ocean water and the near-surface wind speed (Veefkind and de Leeuw, 1998).

For each aerosol model, an AOD is determined by minimising the $\chi^{2}$ merit function obtained with the spectra of measured reflectances, the computed reflectances (function of the AOD), and the error in the measured reflectances.

The aerosol model with the smallest value of $\chi^{2}$ is selected, and the corresponding AOD at 14 different wavelengths is reported as the retrieved AOD. Other reported parameters are the single scattering albedo, the size distribution and the aerosol altitude that are associated with the selected aerosol model.

Aerosol models are post-selected based on a climatology of geographical aerosol distribution (Curier et al., 2008). The accuracy of the AOD retrieved by the OMAERO algorithm is estimated to be larger than 0.1 or $30 \%$ of the AOD value. This is an error estimate that was also used for the TOMS aerosol algorithm (Torres et al., 2005). More information on the OMAERO algorithm and data product may be found in Torres et al. (2007).

\subsection{MISR}

\subsubsection{JPL/GSFC}

The Multi-angle Imaging SpectroRadiometer (MISR) was launched into a sun-synchronous polar orbit in December 1999, aboard the NASA Earth Observing System's Terra satellite. MISR measures upwelling short-wave radiance from Earth in four spectral bands centred at 446, 558, 672, and $866 \mathrm{~nm}$, at each of nine view angles spread out in the forward and aft directions along the flight path, at $70.5^{\circ}, 60.0^{\circ}$, $45.6^{\circ}, 26.1^{\circ}$, and nadir (Diner et al., 1998). Over a period of $7 \mathrm{~min}$, as the spacecraft flies overhead, a $380-\mathrm{km}$-wide swath of Earth is successively viewed by each of MISR's nine cameras. As a result, the instrument samples a very large range of scattering angles (between about $60^{\circ}$ and $160^{\circ}$ at mid-latitudes), providing information about aerosol microphysical properties. These views also capture air-mass factors ranging from one to three, offering sensitivity to optically thin aerosol layers, and allowing aerosol retrieval algorithms to distinguish surface from atmospheric contributions to the top-of-atmosphere (TOA) radiance. Global coverage (to $\pm 82^{\circ}$ latitude) is obtained about once per week.

The MISR standard aerosol retrieval algorithm reports AOD and aerosol type at $17.6 \mathrm{~km}$ resolution, by analysing data from $16 \times 16$ pixel regions of $1.1 \mathrm{~km}$-resolution, MISR top-of-atmosphere radiances (Kahn et al., 2009a). Over dark water, operational retrievals are performed using the 672 and $867 \mathrm{~nm}$ spectral bands, assuming a Fresnel-reflecting surface and standard, wind-dependent glint and whitecap ocean surface models. Coupled surface-atmosphere retrievals are performed using all four spectral bands over most land, including bright desert surfaces (Martonchik et al., 2009), but not over snow and ice. 
MISR AOD has been validated and used over many desert surfaces (Martonchik et al., 2004; Christopher et al., 2008, 2009; Kahn et al., 2009b; Koven and Fung, 2008; Xia et al., 2008; Xia and Zong, 2009), as well as other less challenging environments. Sensitivity to AOD and particle properties varies with conditions; at least over dark water, under good retrieval conditions and mid-visible AOD larger than about 0.15 , MISR can distinguish about three-to-five groupings based on particle size, two-to-four groupings in single scattering albedo (SSA), and spherical vs. non-spherical particles (Chen et al., 2008; Kalashnikova and Kahn, 2006). The algorithm identifies all mixtures that meet the acceptance criteria from a table of mixtures, each composed of up to three aerosol components; the same mixture table is applied for all seasons and locations, over both land and water. Version 22 of the MISR Standard Aerosol Product, used in this study, contains 74 mixtures and eight components (Kahn et al., 2010), including a medium-mode, non-spherical dust optical analogue developed from aggregated, angular shapes and a coarse-mode dust analogue composed of ellipsoids (Kalashnikova et al., 2005).

Cloud screening in the MISR aerosol retrieval algorithm is conservative by design, and includes (1) a radiometric, angle-by-angle reflectance mask with spatially and temporally varying reflectance thresholds, (2) a reflectance-feature elevation mask based on stereo-derived heights, (3) a reflectance angular signature cloud mask, (4) an angle-to-angle smoothness test, and (5) and an angle-to-angle spatial correlation test (Martonchik et al., 2009).

\subsection{MERIS and SeaWiFS}

\subsubsection{LOV}

The MERIS algorithm (Antoine and Morel, 1999) is a full multiple scattering inversion scheme using aerosol models and pre-computed look-up tables (LUTs). It uses the path reflectances in the near infrared, where the contribution of the ocean is null, as well as visible reflectances, where the marine contribution is significant and varying with the chlorophyll content of oceanic water. A technique was proposed by Nobileau and Antoine (2005) to overcome the difficulty in discriminating between absorbing and non-absorbing aerosols. In the present regional application, a climatology is used for water reflectance and error as described in Antoine and Nobileau (2006). After absorption has been detected, the atmospheric correction is restarted using specific sets of absorbing aerosol models (i.e. specific LUTs). The aerosol optical thickness at all wavelengths and the Ångström exponent are then derived.

For non-absorbing aerosol, a set of 12 aerosol models is used from Shettle and Fenn (1979) and Gordon and Wang (1994). This set includes four maritime aerosols, four rural aerosols that are made of smaller particles, and four coastal aerosols that are a mixing between the maritime and the rural aerosols. The mean particle sizes of these aerosols, and thus their optical properties, vary as a function of the relative humidity, which is set to 50, 70, 90 and $99 \%$ (hence the 3 times four models). In addition to these boundarylayer aerosols, constant backgrounds are introduced in the free troposphere $(2-12 \mathrm{~km})$, with a continental aerosol AOD of 0.025 at $550 \mathrm{~nm}$ (WCRP, 1986) and in the stratosphere $(12-30 \mathrm{~km})$, with $\mathrm{H}_{2} \mathrm{SO}_{4}$ aerosol AOD of 0.005 at $550 \mathrm{~nm}$ (WCRP, 1986).

For the absorbing case, the look-up tables use the six dust models and the three vertical distributions proposed by Moulin et al. (2001), which were derived as the most appropriate to reproduce the TOA total radiances recorded by SeaWiFS above thick dust plumes off western Africa. The mean Ångström exponent of these models is about 0.4 when computed between 443 and $865 \mathrm{~nm}$. When these aerosols are present, a background of maritime aerosol is maintained, using the Shettle and Fenn (1979) maritime model for a relative humidity of $90 \%$ and an optical thickness of 0.05 at $550 \mathrm{~nm}$ (Kaufman et al., 2001). The backgrounds in the free troposphere and the stratosphere are unchanged.

A specific test using the band at $412 \mathrm{~nm}$ was developed in order to eliminate clouds without eliminating thick dust plumes (see also Nobileau and Antoine, 2005), which are quite bright in the near infrared and therefore are eliminated when using a low threshold in this wavelength domain (as done for instance in the standard processing of the SeaWiFS observations). The same algorithm is applied to SeaWiFS. In this case, specific look-up tables are used that correspond to the SeaWiFS band set. This is the only difference as compared to the MERIS version.

\subsection{MODIS}

\subsubsection{NASA-GSFC}

In this intercomparison, the Deep Blue retrievals (Hsu et al., 2004, 2006) have been considered, and this dataset includes only data over land. The principal concept behind the Deep Blue algorithm's retrieval of aerosol properties over surfaces such as arid and semi-arid takes advantage of the fact that, over these regions, the surface reflectance is usually very bright in the red part of the visible spectrum and in the near infrared, but is much darker in the blue spectral region (i.e. wavelength less than $500 \mathrm{~nm}$ ). In order to infer atmospheric properties from these data, a global surface reflectance database of $0.1^{\circ}$ latitude by $0.1^{\circ}$ longitude resolution was constructed over land surfaces for visible wavelengths using the minimum reflectivity technique (for example, finding the clearest scene during each season for a given location). For MODIS collection 5.1 Deep Blue products, the surface BRDF effects are taken into account by binning the reflectivity values into various viewing geometries.

Cloud masks used in the Deep Blue algorithm are different from the standard MODIS cloud masks. They are generated 
internally and consist of three steps: (1) determining the spatial variance of the $412 \mathrm{~nm}$ reflectance; (2) using the visible aerosol index $(412-470 \mathrm{~nm})$ to distinguish heavy dust from clouds; and (3) detecting thin cirrus based on the $1.38 \mathrm{mi}-$ cron channel reflectance. After cloud screening, the aerosol optical depth and aerosol type are then determined simultaneously in the algorithm using look-up tables to match the satellite-observed spectral radiances. The final products include spectral aerosol optical depth, Ångström exponent, as well as single scattering albedo for dust. More information on the Deep Blue algorithm can be found at Hsu et al. $(2004,2006)$.

\subsection{SEVIRI}

\subsubsection{GlobAEROSOL}

The DRI intercomparison has made use of the SEVIRI GlobAEROSOL product. This is derived using the OxfordRAL Aerosol and Cloud optimal estimation retrieval scheme. A full description of the retrieval is given by Thomas (2009). It makes use of the $0.64,0.81$ and 1.64 micron channels of SEVIRI at 10:00, 13:00 and 16:00 UTC. The forward model includes a BRDF description of the surface reflectance, and, by constraining the relative strengths of the direct, hemispherical and bi-hemispherical surface reflectance to a priori values, the aerosol optical depth, effective radius and the surface reflectance in each channel can be retrieved. The a priori surface reflectance is determined by the 16-day MODIS BRDF product over land and by an ocean surface reflectance model over the ocean.

Retrievals are done for each of five predefined aerosol types: desert dust, maritime clean, continental clean, and urban, all using components properties from the Optical Properties of Aerosols and Clouds (OPAC) database (Hess et al., 1998) and biomass-burning (from Dubovik et al., 2006). From these five results, a best match is selected based on the quality of the fit to the measurements and a priori constraints, providing a crude speciation of the aerosol.

Cloud screening is performed with the standard EUMETSAT flag (EUMETSAT, 2007) and using the "opening test" (in addition to the usual quality control measures) to get rid of residual cloud, as documented in ESTEC (2006).

\subsubsection{ORAC}

The SEVIRI-ORAC dataset represents an updated version of the aerosol retrieval algorithm used in SEVIRIGlobAEROSOL. The main difference is the addition of infrared channels that improve the retrieval over bright surfaces. A simultaneous aerosol retrieval that considers the visible, near-infrared and mid-infrared channels $(0.64,0.81$, $1.64,10.78,11.94$ micron) is used, as described in detail by Carboni et al. (2007).
The main difference from the GlobAEROSOL algorithm is the addition of two IR channels around 11 and 12 microns (assuming surface emissivity equal to ocean emissivity). For these infrared channels, ECMWF profile and skin temperature are used to define the clear sky atmospheric contribution to the signal. Together with AOD at $550 \mathrm{~nm}$ and effective radius, the altitude of the aerosol layer and surface temperature are part of the state vector of retrieved parameters. The retrieval is performed only with the desert dust aerosol class (spherical particles): this will produce errors in non-dust conditions, and in particular will produce an overestimation of AOD in clean conditions and more scattering aerosol type (non-dust). In this dataset, only the SEVIRI scenes acquired at 12:12 UT are analysed to allow the maximum thermal contrast and with no need for interpolation of ECMWF data.

A data cut is then performed, excluding pixels that result in AOD greater than 4.9, AOD less the 0.01, effective radius greater the $3 \mu \mathrm{m}$, brightness temperature difference at 11-12 microns greater than $1.2 \mathrm{~K}$, cost function greater than 15 and pixels where the retrieval is not converging.

\subsubsection{IMPERIAL}

Two different retrieval schemes are employed depending on whether the SEVIRI observations are taken over land or over ocean. In both cases, retrievals are only performed if the scene is designated non-cloudy. Over ocean, the cloud detection scheme described by Ipe et al. (2004) is utilised in conjunction with a subsequent test to restore any dusty points incorrectly flagged as cloud (Brindley and Russell, 2006). Over land, the scheme of Ipe et al. (2004) is supplemented by the cloud detection due to Derrien and Le Gleau (2005). Again, dusty points incorrectly flagged as cloud are restored based on the threshold tests developed under the auspices of the Satellite Application Facility for Nowcasting (Meteofrance, 2005).

\section{Imperial VIS}

Over ocean, optical depths at $0.6,0.8$ and 1.6 microns are obtained independently from the relevant channel reflectances according to the algorithm described in Brindley and Ignatov (2006). Briefly, this scheme involves the use of reflectance look-up tables (LUTs) derived as a function of solar/viewing geometry and aerosol optical depth. For a given sun-satellite geometry and channel, the retrieved optical depth is that which minimises the residual between the observed and simulated reflectance. One fixed "semiempirical" aerosol model is used in the construction of the LUTs, matching the representation originally employed in the retrieval scheme developed for the Advanced Very High Resolution Radiometer (AVHRR) (Ignatov and Stowe, 2002). Using the optical depths derived from the different channels, one can also obtain estimates of Ångström 
coefficients: these can subsequently be used to scale the retrievals to alternative wavelengths as required. De Paepe et al. (2008) show that retrievals using this method exhibit RMS differences with co-located MODIS optical depths that are typically less than 0.1 .

\section{Imperial IR}

Over land, the lack of contrast between aerosol and surface reflectance in the solar bands makes it difficult to use these alone to obtain a quantitative measure of aerosol loading. Instead, a relatively simple method is used that relates dust-induced variations in SEVIRI 10.8 and 13.4 micron brightness temperatures to the visible optical depth (Brindley and Russell, 2009). This technique essentially builds on the method originally developed for Meteosat by Legrand et al. (2001), but attempts to eliminate the impact of variations in the background atmospheric state on the brightness temperature and hence optical depth signal. Comparisons with co-located AERONET and aircraft measurements (Brindley and Russell, 2009; Christopher et al., 2011) indicate a maximum uncertainty of $\sim 0.3$.

\subsection{POLDER/PARASOL}

The instrument on the PARASOL platform (Polarization and Anisotropy of Reflectances for Atmospheric Science coupled with Observations from a Lidar), which is the second in the CNES Myriade line of microsatellites, is largely based on the POLDER instrument (Deschamps et al., 1994). The chargecoupled device (CCD) has been rotated by $90^{\circ}$ to allow a larger scattering angle range, and the spectral range (440 to $910 \mathrm{~nm}$ ) has been extended up to $1020 \mathrm{~nm}$. Its two main factors are the ability to measure the linear polarisation of the radiance in three spectral bands, 490,670 and $865 \mathrm{~nm}$, and to acquire the directional variation of the total and polarized reflected radiance. The instrument concept is based on a wide field of view lens and a bi-dimensional CCD that provides an instantaneous field of view of $\pm 51^{\circ}$ along-track and $\pm 43^{\circ}$ cross-track. As the instrument flies over the target, up to 16 views are acquired which can be composed to infer the directional signature of the reflectance. This signature provides information on the surface, aerosol, and cloud characteristics. A limitation of POLDER is the rather crude spatial resolution of about $6 \mathrm{~km}$. The POLDER instrument flew on-board the ADEOS 1 and 2 platforms in 1996-1997 and 2003, respectively. Unfortunately, due to the failure of the satellite solar panels, the measurement time series are limited to respectively 8 and 7 months. The microsatellite PARASOL was launched in December 2004; it is still operating and has been part of the A-train since December 2009.

Algorithms have been developed to process the sun radiances reflected by the Earth's surface and atmosphere in terms of aerosol products (Deuzé et al., 2001; Herman et al., 2005). We describe in more detail how the specific characteristics of POLDER have been used to retrieve aerosol properties.

\subsubsection{Aerosol over the oceans}

The combination of spectral-directional and polarized signature provides a very strong constraint to invert the aerosol load and characteristics. The present algorithm (Herman et al., 2005) assumes spherical or non-spherical particles, nonabsorbing particles, and the size distribution follows a combination of two log-normal aerosol size distributions in the accumulation and coarse modes respectively. In a first step, the retrieval of optical depth and size distribution is achieved using radiance measurements in two aerosol channels, 670 and $865 \mathrm{~nm}$. When the geometrical conditions are optimum, i.e. when the scattering angle coverage is larger than $125^{\circ}$ $155^{\circ}$, the shape (spherical or not) of the particles is derived. In a second step, the refractive index retrieval is attempted from the polarisation measurements.

Comparisons with AERONET measurements show very good agreement, with typical RMS errors less than 0.10 , including errors due to cloud cover or time difference acquisition within $\pm 1 \mathrm{~h}$, with no significant bias. With an additional removal of cloud-contaminated cases, the statistical RMS error is close to 0.03 . The fine mode optical depth can also be compared to AERONET measurements, albeit with some uncertainty on the aerosol radius cut-off. Statistical results indicate a low bias of 0.02 with a standard deviation of 0.02 .

The combination of spectral, directional and polarisation information has been used to attempt a retrieval of the aerosol refractive index over the oceans. The results indicate that, when the coarse mode is spherical, the refractive index is close to that of water (1.35), indicating hydrated particles. When the coarse mode is mostly non-spherical, however, the retrieval is found to be inconclusive. As for the fine mode, the inverted refractive index is generally found between 1.40 and 1.45 , with no clear spatial distributions.

\subsubsection{Aerosol over land}

The retrieval of aerosol load properties over land surface is based on polarized reflectance measurements. When the surface reflectance is generally larger than that generated by aerosols, which makes quantification difficult from radiance measurements alone, the polarized reflectance of land surfaces is moderate and spectrally constant, although with a very strong directional signature (Nadal and Bréon, 1999). On the other hand, scattering by submicron aerosol particles generates highly polarized radiance (Deuzé et al., 2001), which makes it possible to estimate the corresponding load. Nevertheless, larger aerosol particles, such as desert dust, do not nearly polarize sunlight and are therefore not accessible to a quantitative inversion from POLDER measurements. In addition, the polarized reflectance of bright surfaces is larger 
Table 2. Summary of dataset main characteristics: assumptions, cloud screening, retrieved parameters besides the AOD at $550 \mathrm{~nm}$ and the spectral range together with other mean features of the instrument that have been used (for more details see individual algorithm description in Sect. 2).

\begin{tabular}{|c|c|c|c|c|}
\hline DATASET & Assumptions & Cloud screening & Parameters retrieved & Spectral range \\
\hline AATSR-GLOB & Over land MODIS-BRDF as a priori & $\begin{array}{l}\text { ESA operational cloud flag, } \\
\text { opening test }\end{array}$ & $\begin{array}{l}\text { Reff, } \\
\text { Aerosol type, } \\
\text { bi-hemispheric albedo (ch) }\end{array}$ & VIS-NIR, 2 views \\
\hline AATSR-ORAC & Over land MODIS-BRDF as a priori & ESA operational cloud flag & $\begin{array}{l}\text { Reff } \\
\text { Aerosol type, } \\
\text { bi-hemispheric albedo (ch) }\end{array}$ & VIS-NIR, 2 views \\
\hline AATSR-SWA & Reff & GLOBCARBON cloud detection system & $\begin{array}{l}\text { Aerosol type } \\
\text { surface reflectance }(\mathrm{ch})\end{array}$ & VIS-NIR, 2 views \\
\hline AIRS & $\begin{array}{l}\text { Height, } \\
\text { Reff }\end{array}$ & BTD & $\operatorname{AOD}(10 \mu \mathrm{m})$ & TIR \\
\hline MERIS-LOV & $\begin{array}{l}\text { Fixed particle size (varies with the } \\
\text { humidity) }\end{array}$ & Test at $412 \mathrm{~nm}$ & Chlorophyll content & VIS-NIR \\
\hline MISR & & $\begin{array}{l}\text { angle-by-angle reflectance mask, } \\
\text { elevation mask based on stereo-derived heights, } \\
\text { reflectance angular signature cloud mask, } \\
\text { angle-to-angle smoothness test, } \\
\text { angle-to-angle spatial correlation test }\end{array}$ & $\begin{array}{l}\text { Aerosol type, } \\
\text { mixture of components, } \\
\text { spherical vs. non-spherical particles }\end{array}$ & VIS, 9 views \\
\hline MODIS & Global surf. refl. dataset + BRDF & $\begin{array}{l}\text { spatial variance at } 412 \mathrm{~nm} \text {, } \\
\text { visible aerosol index }(412-470 \mathrm{~nm}) \text {, } \\
1.3, \mu \mathrm{m} \text { to detect cirrus }\end{array}$ & & $\begin{array}{l}\text { VIS, Deep Blue } \\
\text { wavelengths }\end{array}$ \\
\hline OMI-KNMI & Land surf. refl. From MISR data & $\begin{array}{l}\text { reflectance and UV AAI } \\
\mathrm{O} 2-\mathrm{O} 2 \text { cloud product } \\
\text { spatial homogeneity }\end{array}$ & $\begin{array}{l}\text { Aerosol type } \\
\text { SSA } \\
\text { height } \\
\text { size distribution of the best fit }\end{array}$ & UV-VIS \\
\hline OMI-NASA & $\begin{array}{l}\text { TOMS surf. refl. } \\
\text { dust height from GOCART }\end{array}$ & $\begin{array}{l}\text { Internal cloud mask over land } \\
\text { UVAI }>1 \text { over ocean }\end{array}$ & $\begin{array}{l}\text { AOD }(388 \mathrm{~nm}) \\
\text { SSA }(388 \mathrm{~nm})\end{array}$ & UV \\
\hline POLDER-LAND & $\begin{array}{l}\text { log-normal size distribution (fine), } \\
\text { combination of a priori } \\
\text { surface BRDF }\end{array}$ & $\begin{array}{l}\text { thresholds (total and polarized reflectances), } \\
\text { detection of the polarized rainbow, } \\
\text { apparent pressure (O2 absorption band) }\end{array}$ & Ångström coeff. & $\begin{array}{l}\text { VIS-NIR, up to } 16 \\
\text { views } \\
\text { normal and polar- } \\
\text { ized channels }\end{array}$ \\
\hline POLDER-OCEAN & $\begin{array}{l}\text { combination of two } \\
\text { log-normal } \\
\text { size distributions (fine and coarse) }\end{array}$ & $\begin{array}{l}\text { thresholds (total and polarized reflectances), } \\
\text { detection of the polarized rainbow, } \\
\text { spatial variability of reflectance }\end{array}$ & $\begin{array}{l}\text { Ångström coeff., } \\
\text { Reff }\end{array}$ & $\begin{array}{l}\text { VIS-NIR, up to } 16 \\
\text { views } \\
\text { normal and polar- } \\
\text { ized channels }\end{array}$ \\
\hline SEAWIFS & $\begin{array}{l}\text { Fixed particle size (varies with hu- } \\
\text { midity) }\end{array}$ & Test at $412 \mathrm{~nm}$ & Chlorophyll content & VIS-NIR \\
\hline SEVIRI-IMP-IR & $\begin{array}{l}\text { Fixed aerosol model, } \\
\text { ECMWF data }\end{array}$ & $\begin{array}{l}\text { Cloud detection scheme, } \\
\text { test to restore dust points }\end{array}$ & & TIR \\
\hline SEVIRI-IMP-VIS & $\begin{array}{l}\text { Fixed aerosol model, } \\
\text { Fixed BRDF }\end{array}$ & $\begin{array}{l}\text { Cloud detection scheme, } \\
\text { test to restore dust points }\end{array}$ & Ångström coeff. & VIS \\
\hline SEVIRI-GLOB & Over land MODIS-BRDF as a priori & $\begin{array}{l}\text { EUMETSAT cloud flag, } \\
\text { opening test }\end{array}$ & $\begin{array}{l}\text { Reff, } \\
\text { aerosol type, } \\
\text { bi-hemispherical albedo }(550 \mathrm{~nm})\end{array}$ & VIS-NIR \\
\hline SEVIRI-ORAC & $\begin{array}{l}\text { ECMWF profiles, } \\
\text { ECMWF skin temperature as a priori, } \\
\text { over land MODIS-BRDF as a priori }\end{array}$ & Data cut for AOD, Reff, BTD and cost function & $\begin{array}{l}\text { Reff, } \\
\text { bi-hemispherical albedo }(550 \mathrm{~nm}) \text {, } \\
\text { height, } \\
\text { surface temperature }\end{array}$ & VIS-NIR-TIR \\
\hline
\end{tabular}



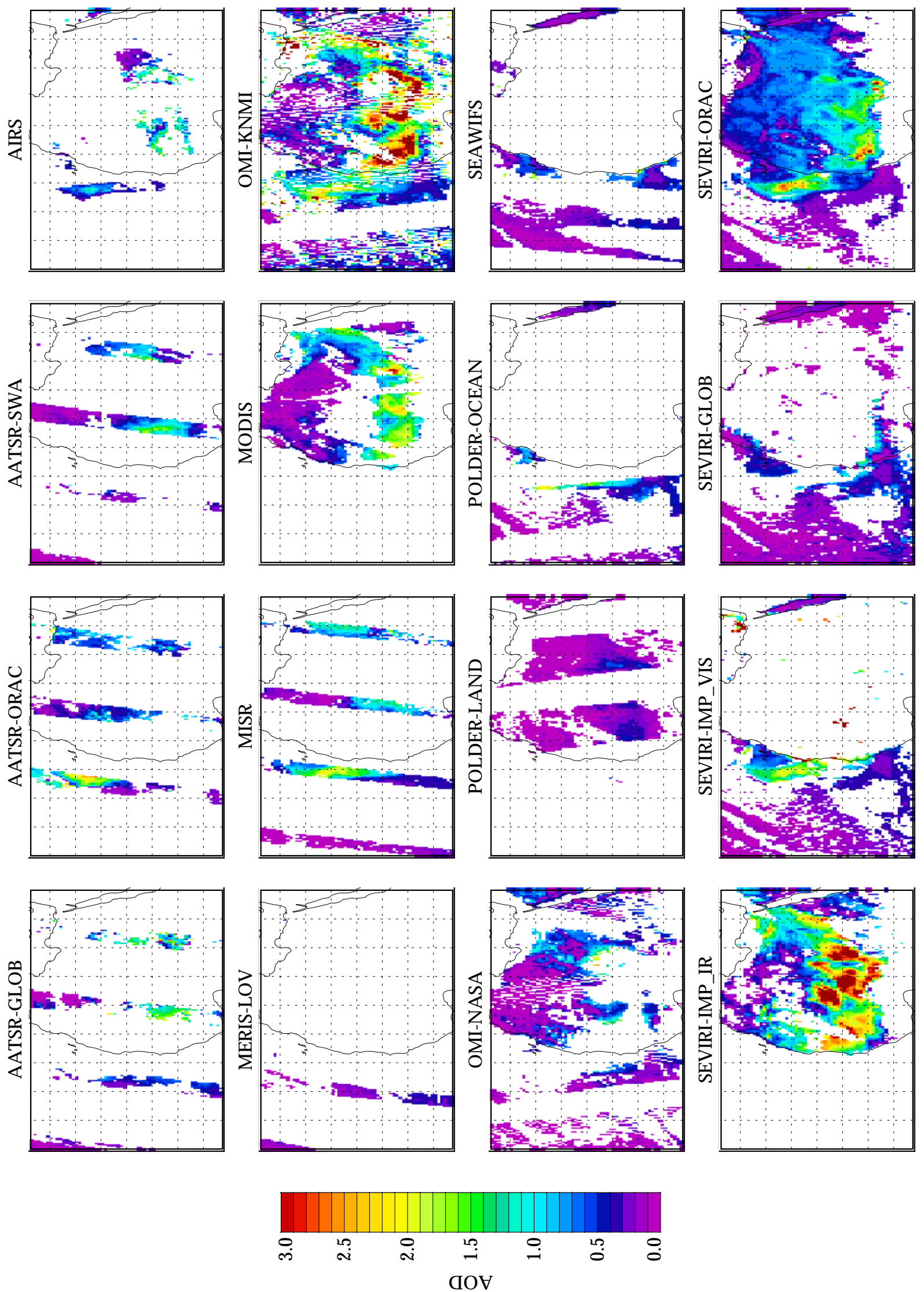

Fig. 1. Image of AOD of the different datasets corresponding to 8 March 2006. 

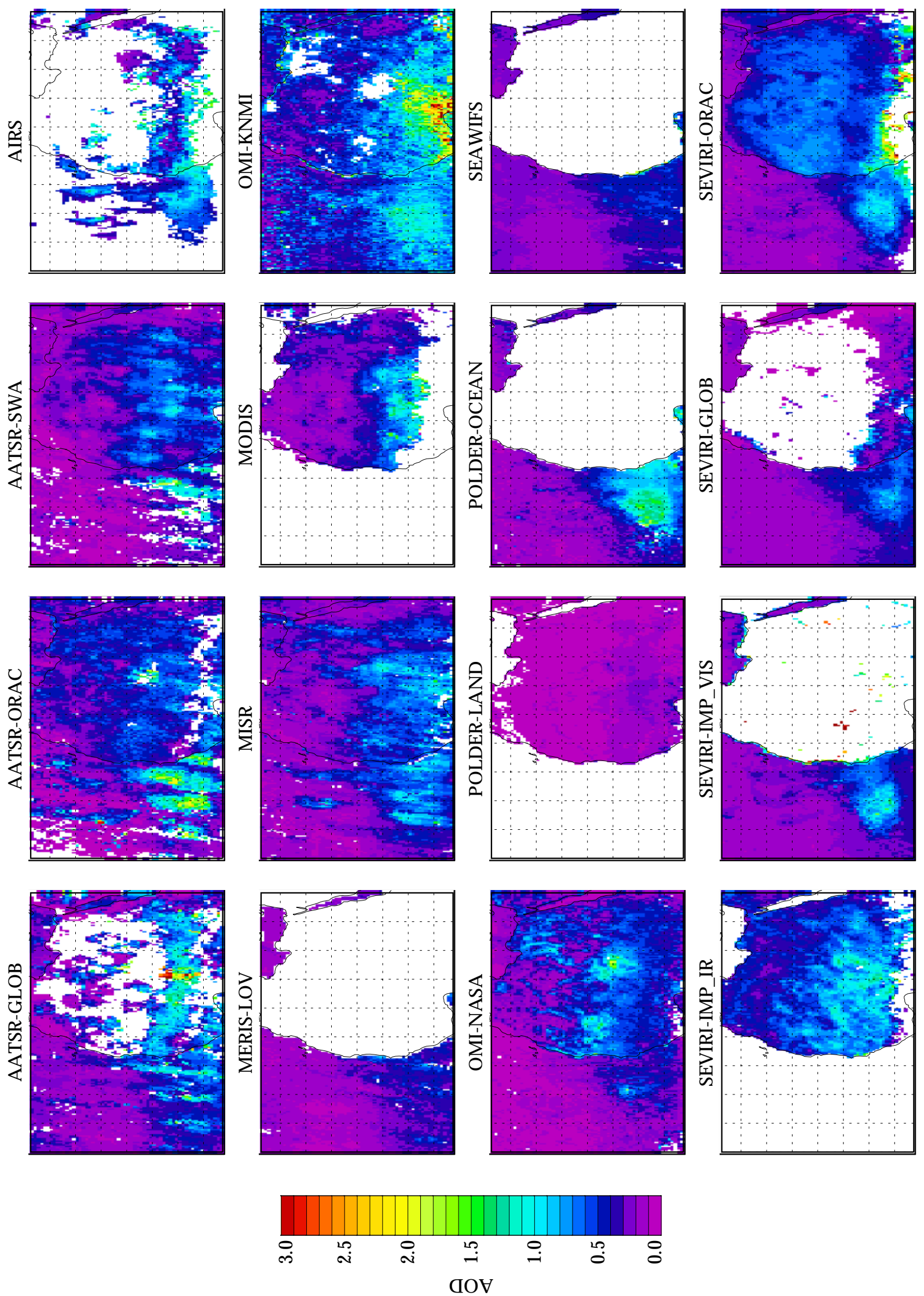

Fig. 2. Image of monthly mean AOD of the different datasets for March 2006. 


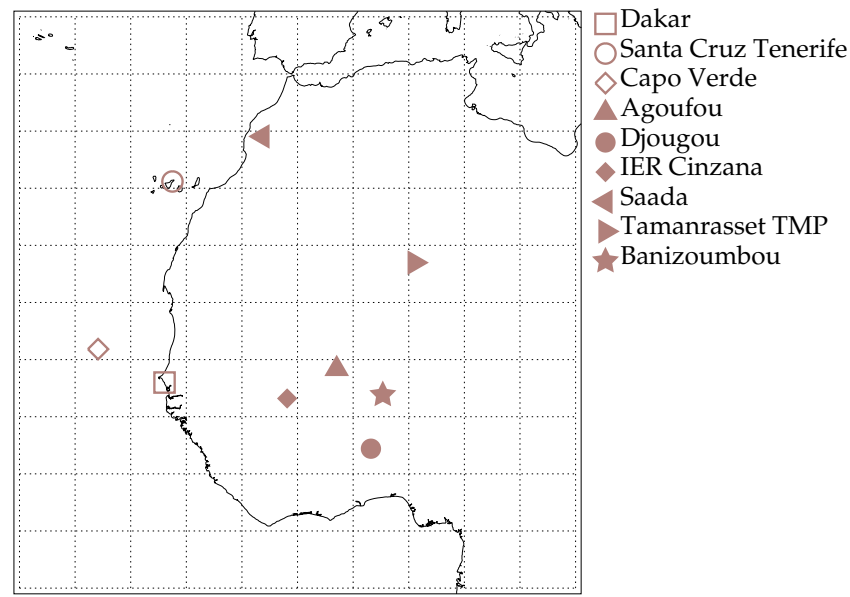

Fig. 3. Location and symbol of the AERONET sites. Every site has a different symbol, consistent with the following AERONET plots: open for coast sites, closed for land sites.

than over vegetated areas, which makes the dust retrieval very challenging. For very strong events dust can bias the accumulation mode retrieval. The retrievals from POLDER measurements show that submicron particles are dominant in regions of biomass burning as well as over highly polluted areas (Tanré et al., 2001). The continuity at the land/sea boundaries is observed in most regions, which gives us good confidence in the quality of the inversions.

Over land, the evaluation of POLDER retrievals is made against the fine mode optical depth derived from AERONET measurements. The results show no significant bias and an RMS error on the order of 0.05 when dust loaded atmosphere is excluded (i.e. a validation in regions affected by biomass burning or pollution aerosols).

Table 2 summarises the principal features of these datasets in terms of main assumptions, cloud screening, other parameters retrieved together with the AOD and the spectral range and mean features of the instruments that have been used.

\section{Results of individual datasets}

Figure 1 shows the $550 \mathrm{~nm}$ AOD for 8 March 2006. This day is a good example of a desert dust plume extending over both land and ocean. The differences in the instrument spatial coverage show how rarely (or how often) there are coincidences between the datasets. There are few coincidences between instruments with narrow swaths (like AATSR vs MISR), while geostationary instruments (SEVIRI) and polar orbiters with a large swath (such as OMI) can give a near complete coverage of the geographic area and have a large number of coincidences with both other satellite datasets and AERONET.

Some care must be taken when comparing the different results in Fig. 1. For instance, AIRS provides AOD at $900 \mathrm{~cm}^{-1}$; it is included in the comparison because it can
Table 3. AERONET sites considered in the comparison: name, latitude, longitude and type (land or coast). The same sites are shown in Fig. 3.

\begin{tabular}{lrrl}
\hline SITE & lat. & long. & type \\
\hline Agoufou & 15.34 & -1.48 & land \\
Banizoumbou & 13.54 & 2.67 & land \\
Capo Verde & 16.73 & -22.94 & coast \\
Dakar & 14.39 & -16.96 & coast \\
Djougou & 9.76 & 1.60 & land \\
IER Cinzana & 13.28 & -5.93 & land \\
Saada & 31.63 & -8.16 & land \\
Santa Cruz Tenerife & 28.47 & -16.25 & coast \\
Tamanrasset TMP & 22.79 & 5.53 & land \\
\hline
\end{tabular}

provide information on AOD of large particles, but a direct comparison with visible AOD (which is far more sensitive to smaller particles) can be misleading. To make a direct comparison, one could rescale the infrared AOD to an effective value at $550 \mathrm{~nm}$, assuming a specific size distribution. Potentially, the different sensitivities of the two ranges could be used to infer information on the size distribution, as attempted by the ORAC-SEVIRI scheme. Similarly, POLDER data over land are particularly sensitive to sub-micron aerosol particles and not the total optical depth.

Here the AIRS AOD and POLDER over land AOD are presented without attempting to scale to optical depth at $550 \mathrm{~nm}$. In scatter plots with other datasets, the "ideal slope" for these instruments is not expected to be one, and if the relative amount of small and large particles changes over the scene, then the correlation will be less than one.

Figure 2 shows the monthly AOD obtained by averaging daily $0.5 \times 0.5$ degree gridded data. Monthly mean dust AOD varies enormously between the datasets. Even over the ocean, where all the retrievals are expected to be more accurate, the monthly AOD inside the area affected by dust (south-west area of the plots) varies from 0.5 (MERIS and SEAWIFS) to 2 (ATSR-ORAC). Some differences are due to instrument sampling, but a large effect arises from the quality control applied to screen the data for "valid" retrievals, as differences between the two OMI datasets show very clearly. MERIS, SEAWIFS and SEVIRI-GLOB frequently cut the dense part of the plume, and this is reflected in the low monthly average AOD.

The AIRS AOD retrieval algorithm is extremely sensitive to the assumed height of the dust layer. In addition, over land, since the algorithm uses window channels, the emissivity of the underlying land can impact the retrieval for cases of low optical depth. One limitation of MODIS Deep Blue Collection 5 is that the surface reflectance database is static and this can be a source of regionally/seasonally dependent error; elevated terrain can also lead to biases as pressure is not accounted for explicitly. The surface reflectance model has been improved for the forthcoming MODIS Collection 

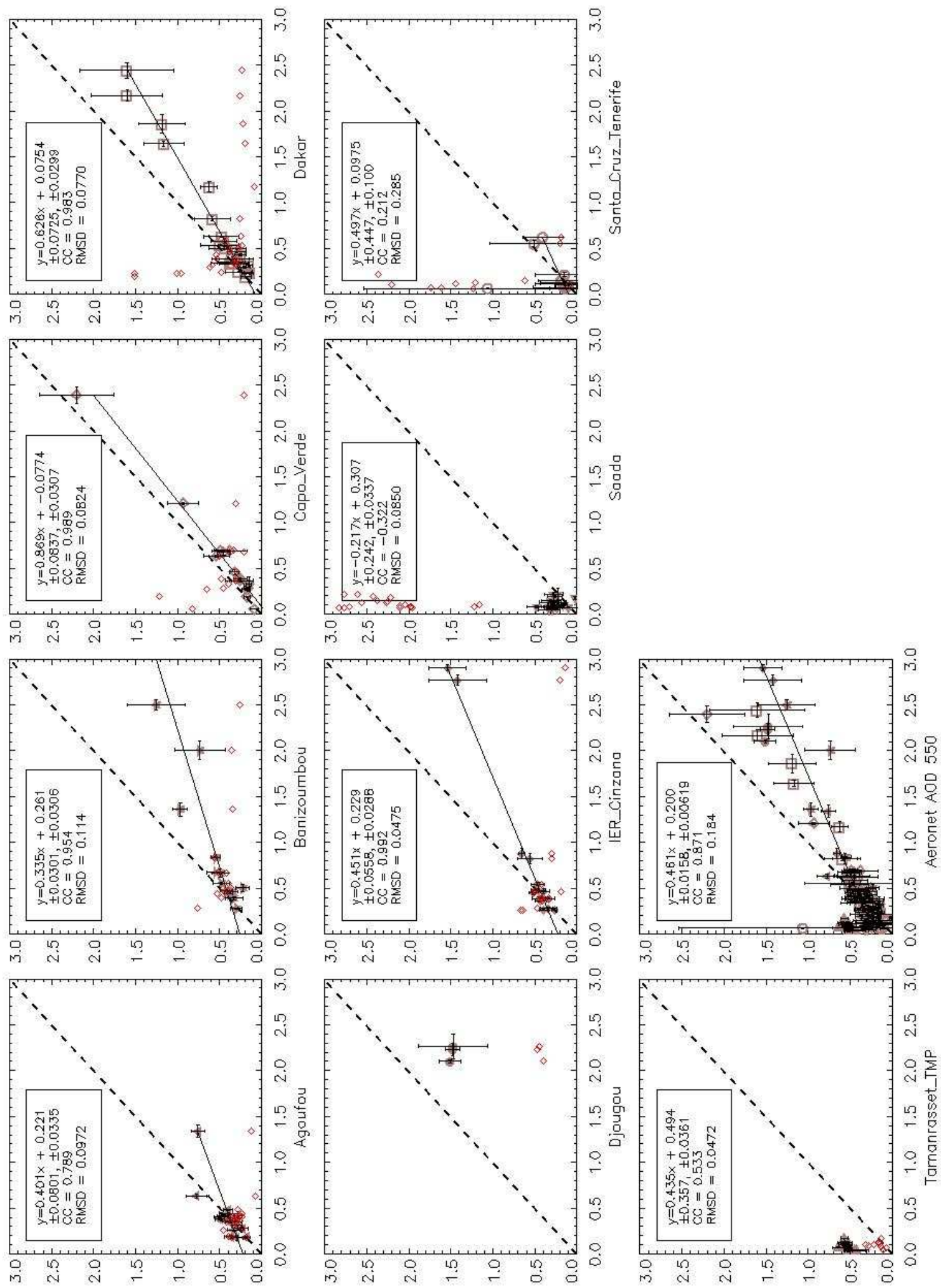

Fig. 4. Example of a scatter plot between AERONET data (x) and satellite (y) for SEVIRI-ORAC. The black/brown symbols are satellite datasets (y) vs. AERONET AOD (x). Different locations are represented by different symbols, as with Fig. 3. The red stars represent two times the AERONET Ångström coefficient (between 440 and $870 \mathrm{~nm}$ ). The final plots show all the coincidences. In every scatter plot with more than four coincidences, there are captions indicating the best linear fit (angular coefficients, y intercept and associated errors), the correlation coefficient (CC) and the root-mean-square differences (RMSD). 

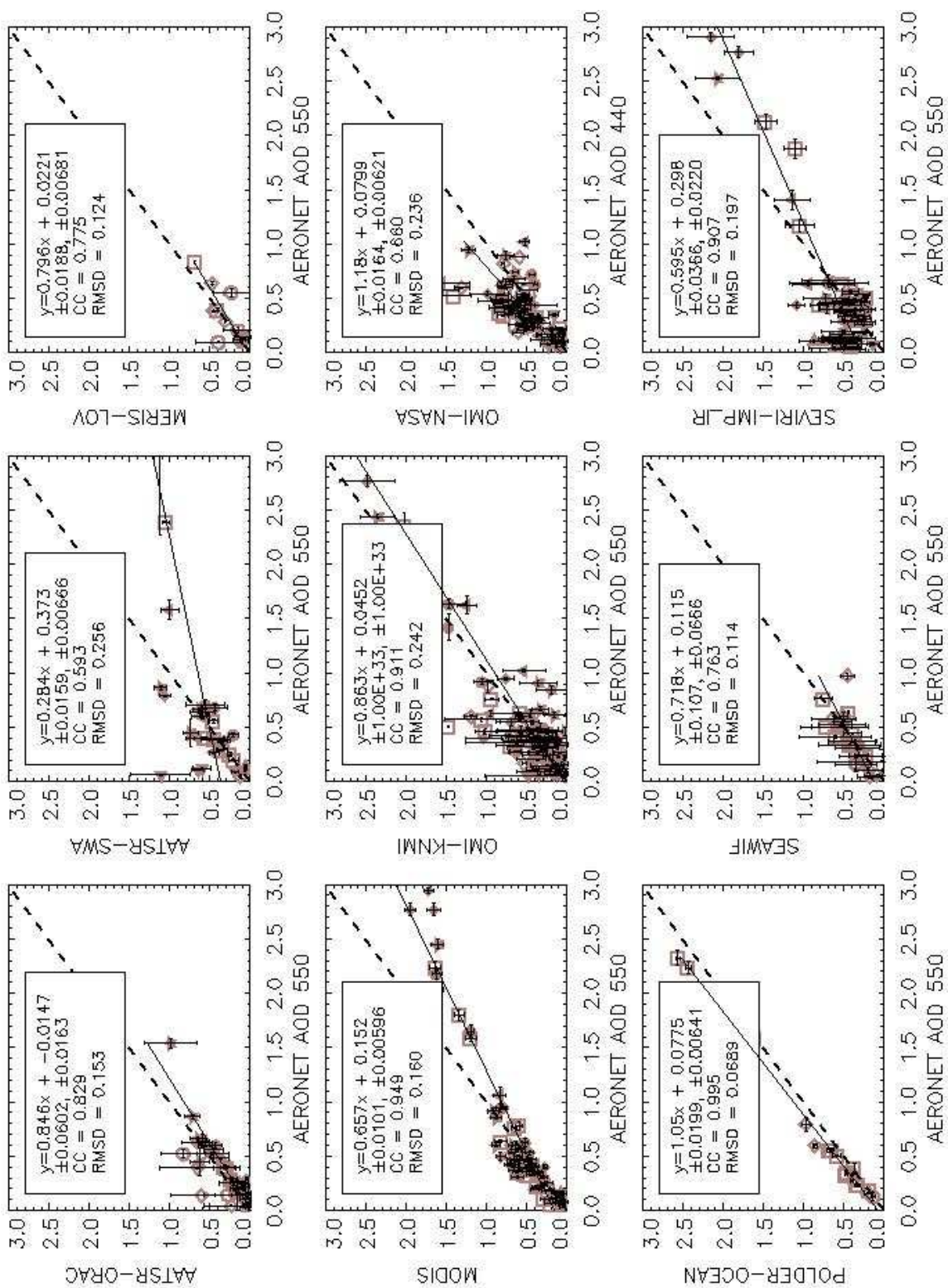

N $\forall \exists \supset O-y \exists 070 d$
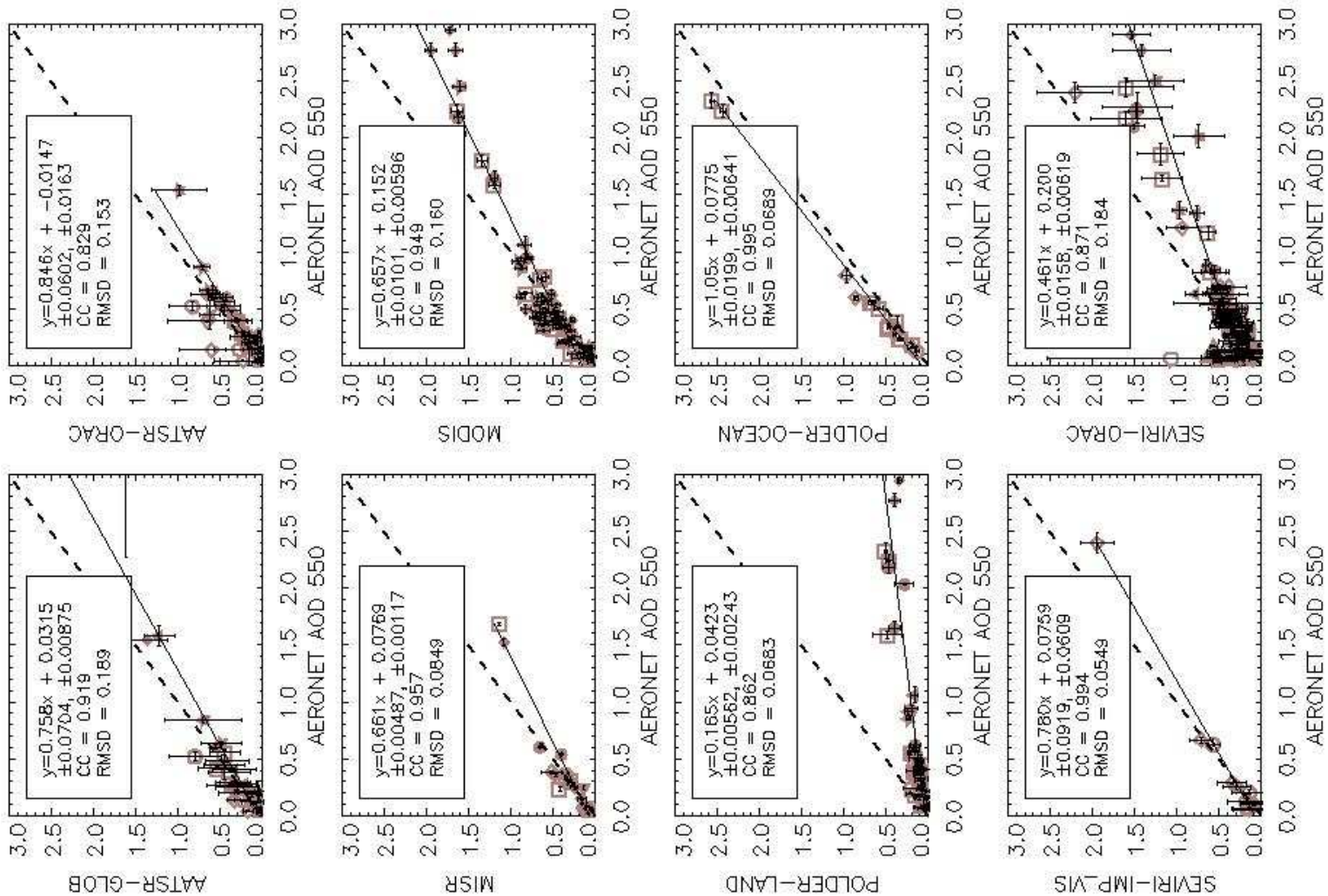

Fig. 5. Scatter plots, satellite datasets AOD (y) vs. AERONET AOD (x), for all the available coincidences. Different locations are represented by different symbols, as defined in Fig. 3. In every scatter plot, there are captions indicating the best linear fit (angular coefficients, y intercept and associated errors), the correlation coefficient (CC) and the root-mean-square differences (RMSD). 

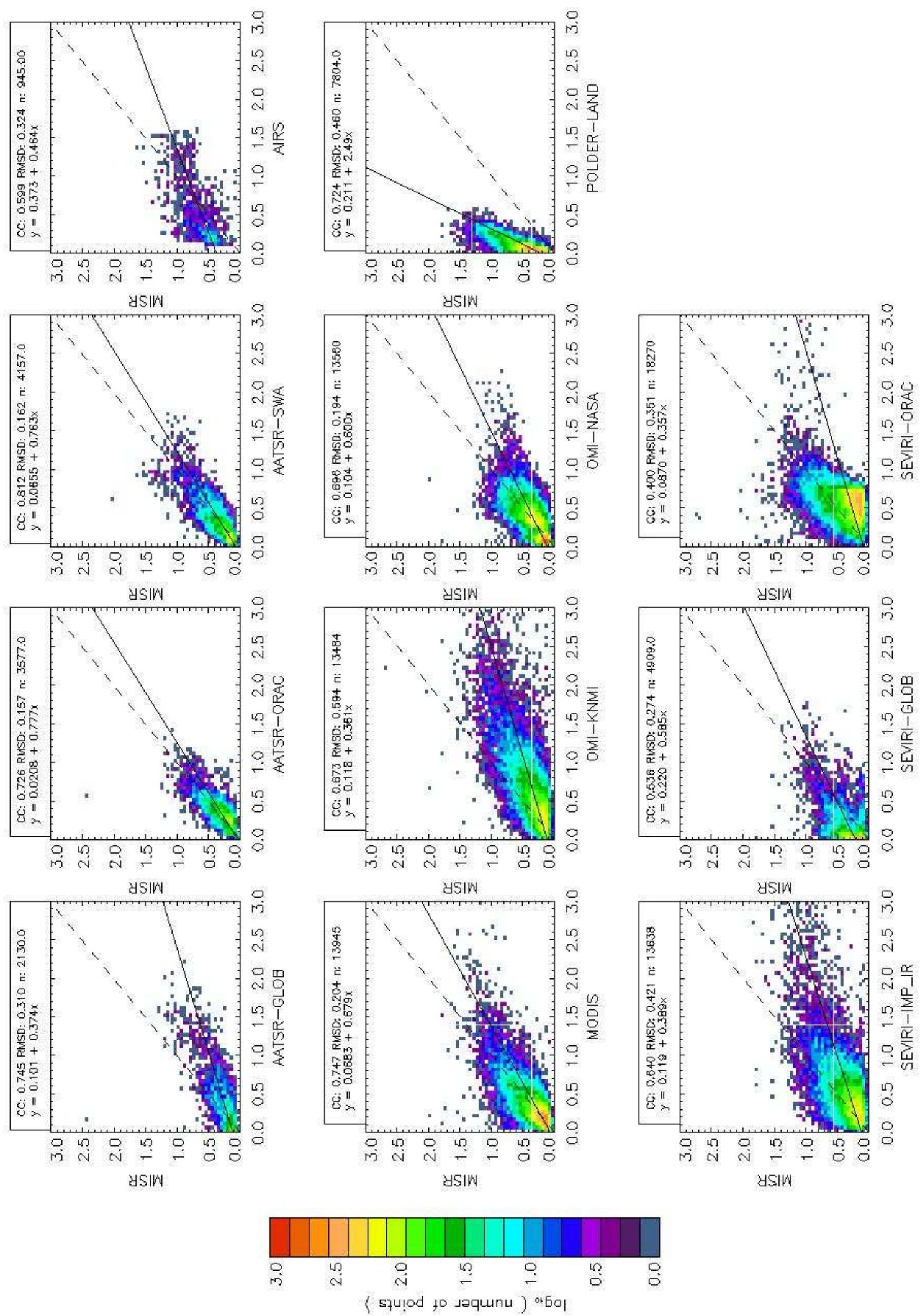

Fig. 6. Example of comparison over land, MISR vs. other datasets. In every scatter plot, there is a caption: the first line indicates the correlation coefficient (CC), the root-mean- square differences (RMSD) and the number of coincidences $(n)$; the second line presents the best linear fit. 

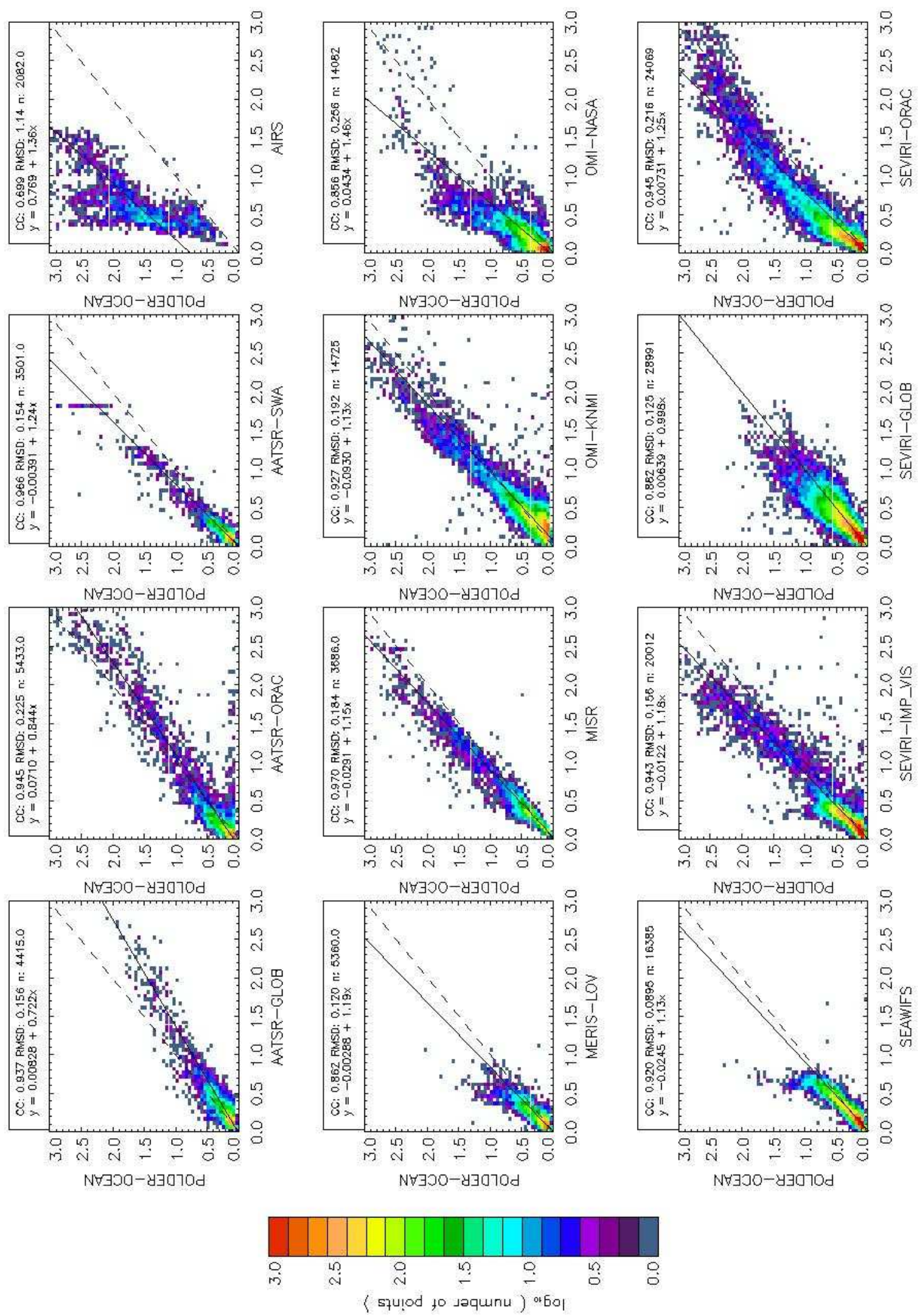

Fig. 7. Example of scatter plots over ocean, POLDER-OCEAN vs. other datasets. In every scatter plot, there is a caption: the first line indicates the correlation coefficient (CC), the root-mean-square differences (RMSD) and the number of coincidences ( $n$ ); the second line presents the best linear fit. 
Table 4. Summary of AOD comparisons for three cases: "all", "very dusty" and "clean" coincidences. " $N$ " is the numbers of coincidences, "CC" the correlation coefficient and "bias" is the absolute mean difference between AERONET and satellite AOD.

\begin{tabular}{lrrrrrrrrr}
\hline & \multicolumn{3}{c}{ All coinc. } & \multicolumn{3}{c}{ Very dusty } & \multicolumn{3}{c}{ Clean } \\
\hline Dataset & $N$ & CC & Bias & $N$ & CC & Bias & $N$ & CC & Bias \\
\hline AATSR-GLOB & 34 & 0.919 & 0.136 & 8 & 0.898 & 0.362 & 9 & 0.581 & 0.060 \\
AATSR-ORAC & 38 & 0.829 & 0.118 & 8 & 0.743 & 0.156 & 8 & 0.728 & 0.061 \\
AATSR-SWA & 49 & 0.593 & 0.316 & 18 & 0.631 & 0.467 & 10 & -0.728 & 0.429 \\
MERIS-LOV & 11 & 0.775 & 0.106 & 3 & & 0.211 & 2 & & 0.029 \\
MISR & 23 & 0.957 & 0.092 & 2 & & 0.493 & 4 & & 0.036 \\
MODIS & 87 & 0.949 & 0.180 & 27 & 0.954 & 0.386 & 18 & 0.836 & 0.037 \\
OMI-KNMI & 104 & 0.911 & 0.189 & 27 & 0.907 & 0.306 & 17 & 0.081 & 0.116 \\
OMI-NASA & 101 & 0.660 & 0.202 & & & & & & \\
POLDER-LAND & 62 & 0.862 & 0.517 & 17 & 0.711 & 1.320 & 8 & 0.693 & 0.088 \\
POLDER-OCEAN & 18 & 0.995 & 0.105 & 8 & 0.995 & 0.150 & 0 & & \\
SEAWIFS & 23 & 0.763 & 0.096 & 8 & 0.014 & 0.119 & 2 & & 0.088 \\
SEVIRI-IMP-IR & 64 & 0.907 & 0.284 & 16 & 0.963 & 0.412 & 7 & 0.952 & 0.316 \\
SEVIRI-IMP-VIS & 11 & 0.994 & 0.085 & 3 & & 0.187 & 4 & & 0.040 \\
SEVIRI-ORAC & 136 & 0.871 & 0.242 & 37 & 0.890 & 0.475 & 27 & -0.265 & 0.133 \\
\hline
\end{tabular}

6, which will decrease this potential error source. AATSR ORAC and SWA have significant better coverage, compared with the same instrument dataset from AATSR-GLOB, due to the better representation of the surface reflectance. A limitation of the MISR dataset is the smoothing mask used in the current version of land retrievals that eliminates high AODs leading to AOD underestimation at high aerosol loading (a problem for heavy dust events). POLDER retrievals are limited over land by the weak sensitivity to the coarse-mode making it impossible to estimate the total AOD, but nevertheless present a good correlation with AERONET data. OMIKNMI is a more complex algorithm than OMI-NASA that makes use of a wider spectral range and fits several aerosol parameters in the retrieval. It has a better coverage of the dust plume compared to OMI-NASA, and, in comparison with the other dataset, OMI-KNMI tends to give higher AOD in the southern part of the region considered in this comparison. MERIS, SEAWIFS, and SEVIRI-IMP-VIS all use visible channels to retrieve the aerosol loading making it difficult to overcome the problem of dust retrieval over bright surface, so these datasets are applied only over ocean. Nevertheless, MERIS and SEAWIFS tend to miss the dust plumes due to presumably too strict quality control while SEVIRI-IMPVIS is able to follow them. SEVIRI-GLOB uses VIS-NIR channels and is applied both over land and ocean but does not cover bright surfaces and also tends to miss the thicker part of the dust plume due to quality control. SEVIRI-IMPIR is applied over land and uses only infrared channels. It works best if the dust loading is relatively large and is less certain when there is little dust in the atmosphere, because it is more dependent on meteorological data. SEVIRI-ORAC is a first attempt to overcome the problem of bright surfaces using VIS and IR channels together, but due to the simple treatment of surface emissivity, the main issue is an overes- timation of AOD over desert in clean conditions, which is attributed to errors in the modelling of surface properties.

\section{AERONET comparison}

A comparison between AERONET level 2, cloud-screened and quality-assured, ground data (Holben et al., 1998; Smirnov et al., 2000) and co-located values for each satellite dataset has been made. Here it is essentially assumed that variability in time is somehow related to variability in space (Ichoku et al., 2002), and an average of all the valid satellite retrievals over a $50 \mathrm{~km}$ radius around each AERONET site has been made. To match the data spectrally, the AODs at $550 \mathrm{~nm}\left(\tau_{550}\right)$ are obtained using AOD at $440 \mathrm{~nm}\left(\tau_{440}\right)$ and Ångström coefficient between 440 and $870 \mathrm{~nm}(\alpha)$ according to

$\tau_{550}=\tau_{440}\left(\frac{0.55}{0.44}\right)^{-\alpha}$

All the AERONET AODs within an interval of half an hour from the satellite overpass time (i.e. a time window of $1 \mathrm{~h}$ ) have been averaged, and all the coincidences with at least two AERONET measurements within this time have been considered. Note that not all satellite datasets have $550 \mathrm{~nm}$ in the spectral range used in the aerosol retrieval: in this case, the AOD at $550 \mathrm{~nm}$ is extrapolated, and this can amplify errors. All the AODs in the AERONET comparisons are reported at $550 \mathrm{~nm}$ except for OMI-NASA, which is reported at $440 \mathrm{~nm}$. Some datasets (see Table 1) have values only over ocean so the comparison is possible only with coastal sites.

Figure 3 shows the location and the symbols that will be used in the scatter plots (Figs. 4 and 5) for the AERONET 


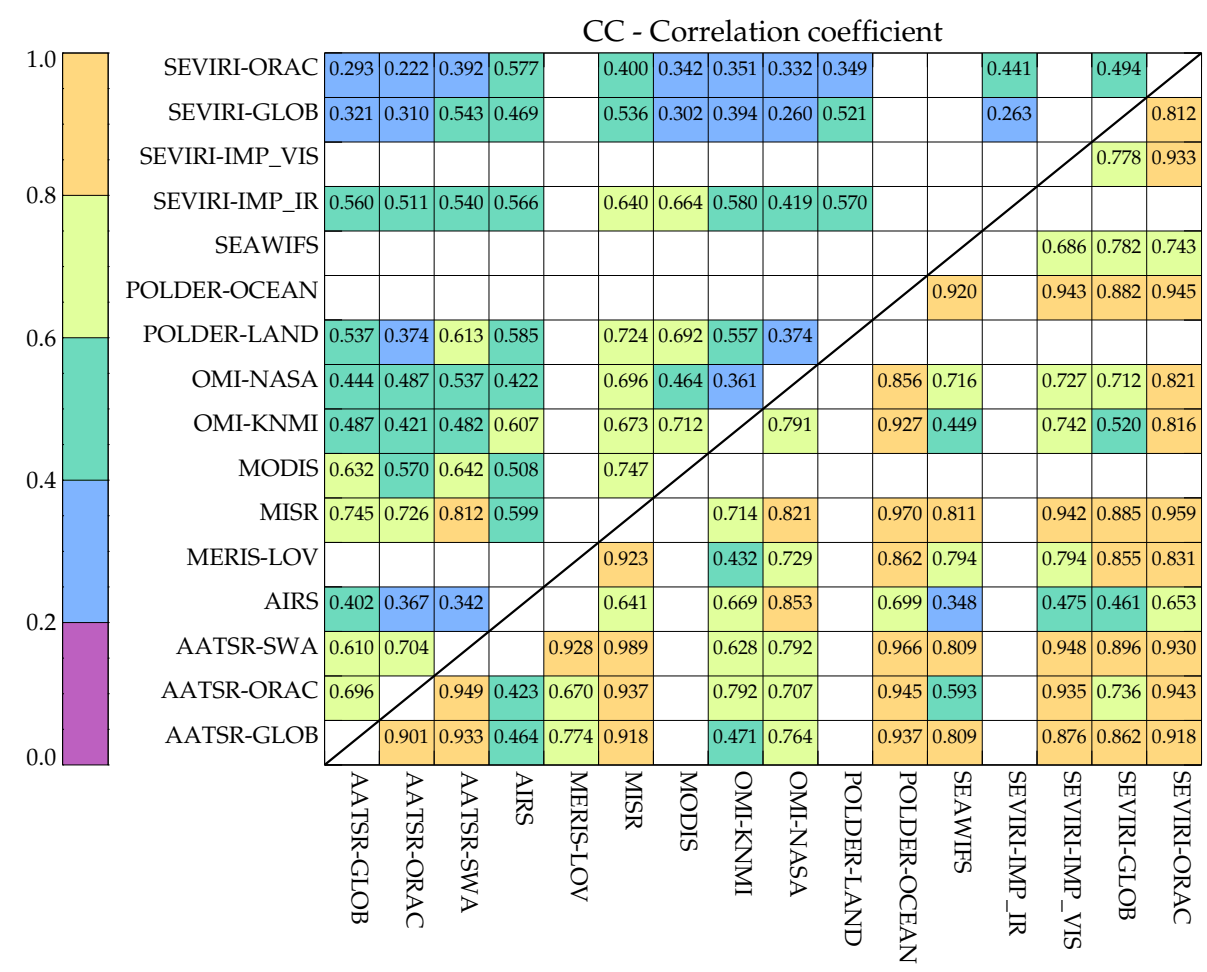

Fig. 8. Correlation coefficient obtained with the comparison of datasets vs. datasets. Values above the diagonal are for data over land, below the diagonal are over ocean.

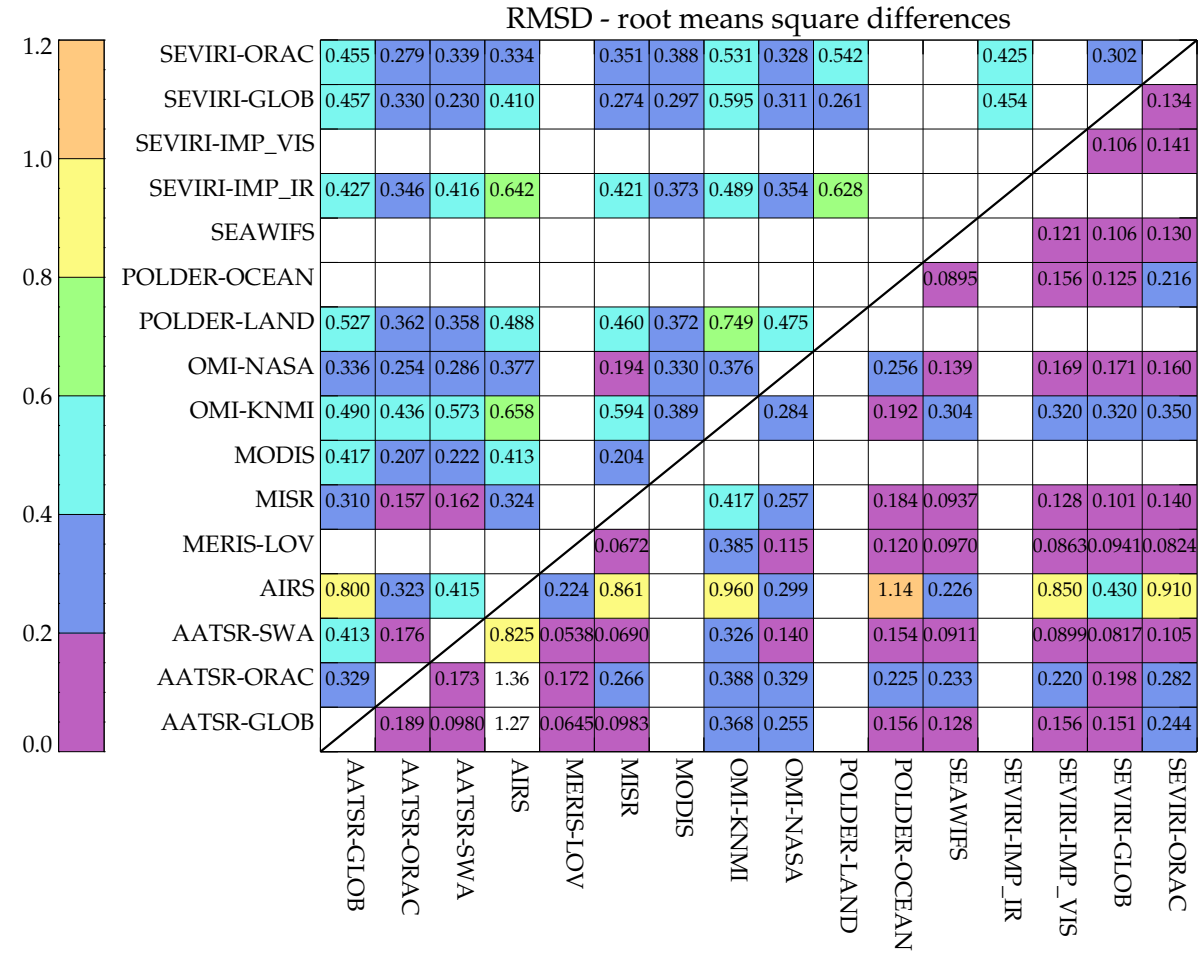

Fig. 9. Root-mean-square difference between different datasets. Values above the diagonal are for data over land, below the diagonal are over ocean. 

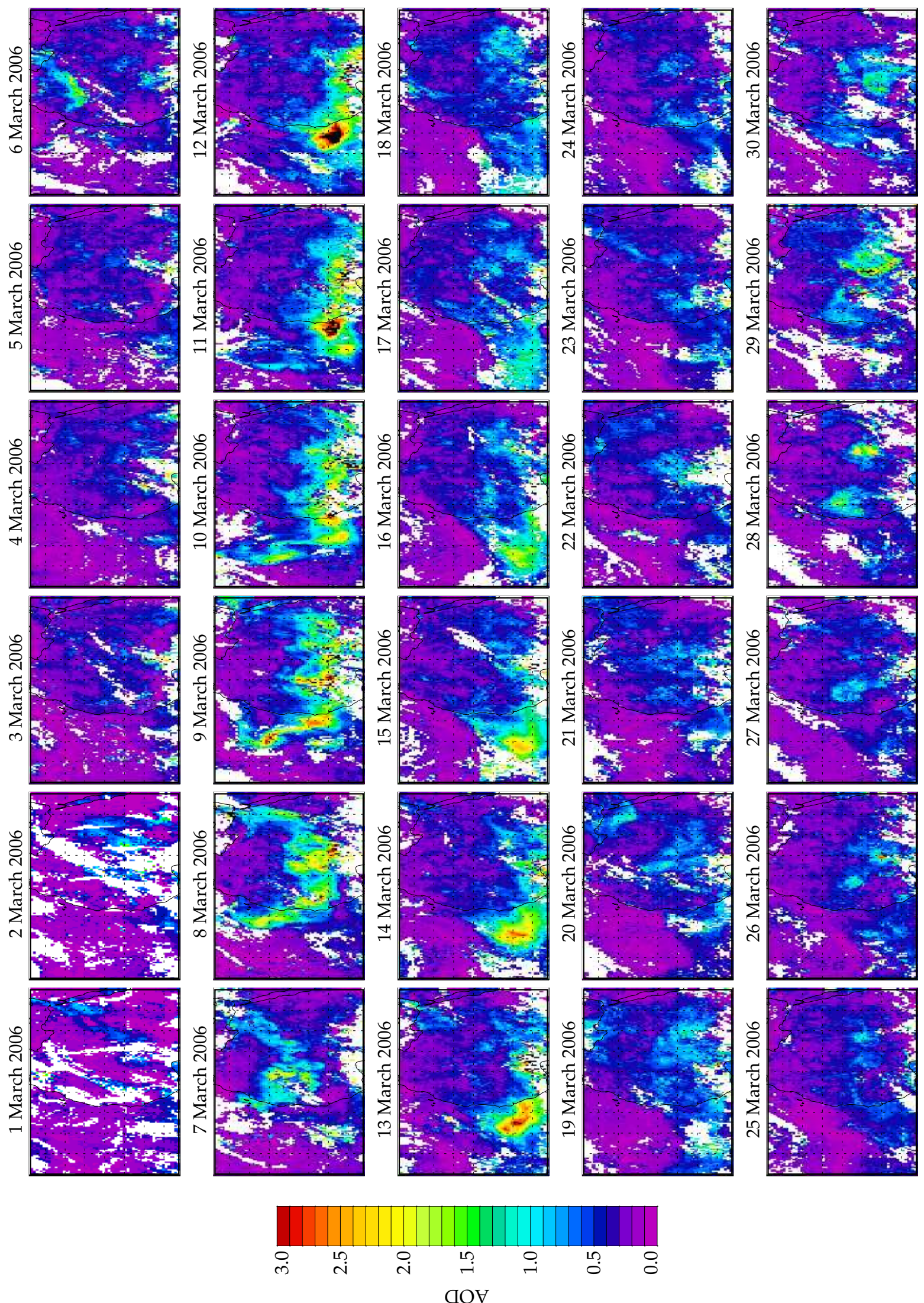

Fig. 10. Combined daily AOD for the first 30 days of March 2006. 

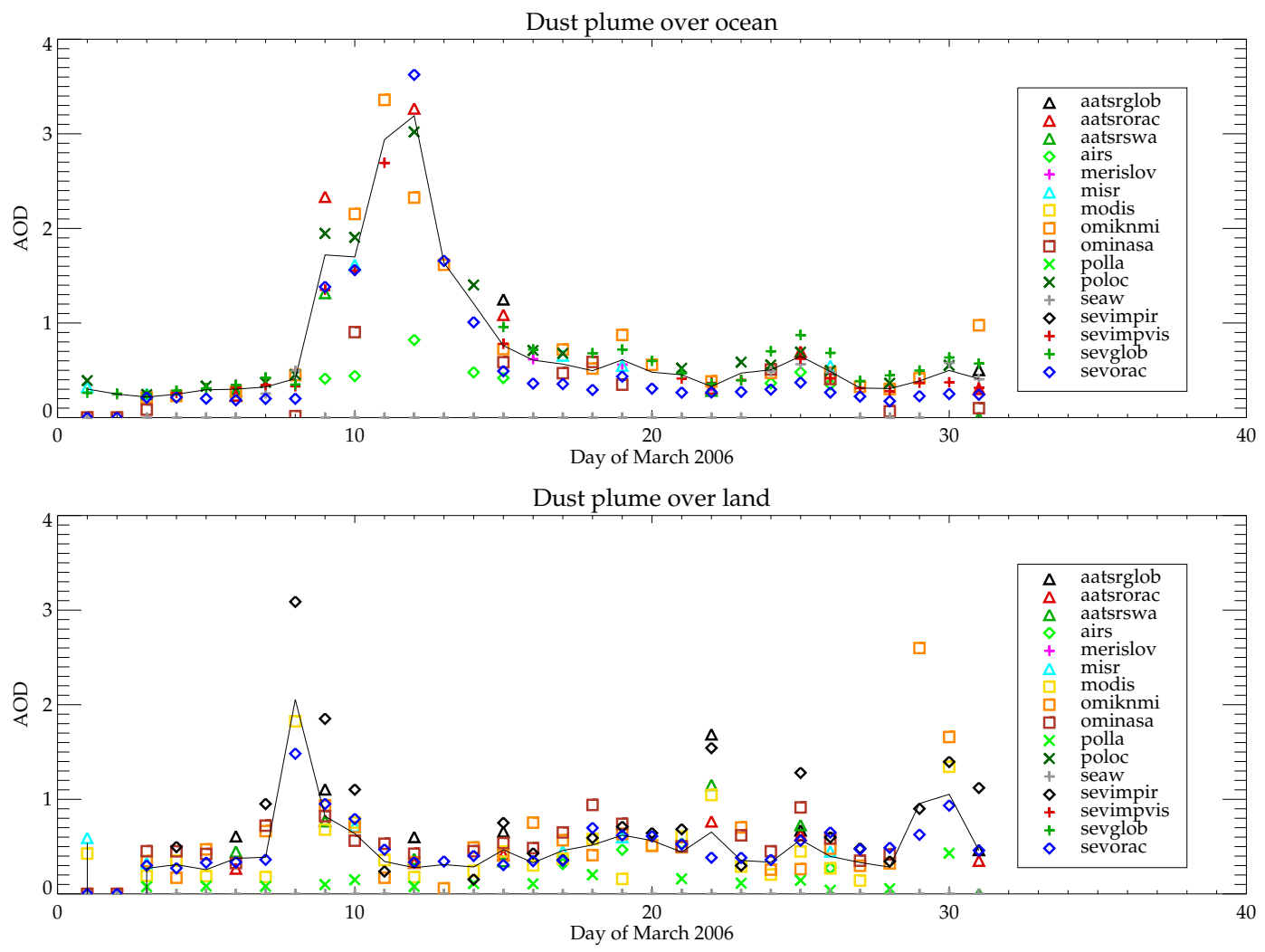

Fig. 11. Evolution of individual dataset AODs and averaged values (black line) as function of day of March 2006.

sites considered. Their coordinates are tabulated in Table 3 together with a classification of land/coast site.

Figure 4 shows an example of satellite vs. AERONET scatter plots for SEVIRI-ORAC. The scatter plots are given for the individual AERONET sites, allowing regional and local issues to be identified. A summary plot is produced using all the coincident data available in all the locations together. On each plot, red stars show the value of two times the AERONET Ångström coefficient (between 440 and $870 \mathrm{~nm}$ ). These values can help to qualitatively distinguish the desert dust measurements (low values) from the smaller particles (high values).

The vertical error bars are the standard deviation (STD) of the satellite measurements (within the area around the AERONET station). The horizontal error bars are the standard deviations of the AERONET measurements (within the $30 \mathrm{~min}$ around the satellite time).

Figure 4 shows that, for AODs values higher than one, SEVIRI-ORAC underestimates the AOD, and does so more over land than over ocean. Looking at the sites with AOD higher than 1, Cinzana and Banizoumbou (land sites) exhibit a larger underestimation, Dakar (on the coast) an intermediate case, and Capo Verde (an island in the ocean) has a slope close to 1 . This behaviour could be the result of imperfect land surface modelling or imperfect modelling of the dust spectral optical properties. Note that the IR channels have more importance in the SEVIRI-ORAC retrieval over land where the visible channels (high surface reflectance) are assumed to be more affected by errors, so correct modelling of the IR optical properties becomes more important over land.

The Saada site appears to be outside the desert storm of March 2006 as shown by the consistently high values of Ångström coefficient. Note that Tamanrasset is at an altitude of $1000 \mathrm{~m}$, which could explain why its observations are biased compared to nearby satellite observations. In the case of a desert plume flowing close to the surface (common during winter time), dust can flow around Tamanrasset and result in a significant amount of dust below the AERONET site.

Similar analyses have been performed for each of the datasets against coincident AERONET measurements: a summary is presented in Fig. 5.

POLDER over land is included for completeness, but one should take into account the fact that the polarisation-based measurement is sensitive only to small particles (fine mode), so the resulting AOD is a fraction of the total aerosol AOD.

Figure 5 shows all the coincidences together for all the datasets available in order to check the overall quality of the satellite retrievals. Not surprisingly, the best agreements are for coast AERONET sites (Capo Verde, Dakar and Tenerife) and ocean only datasets (MERIS-LOV, POLDER-OCEAN, SEAWIFS, SEVIRI-IMP-VIS) where the retrieval is more accurate than over land. With the datasets that consider both 

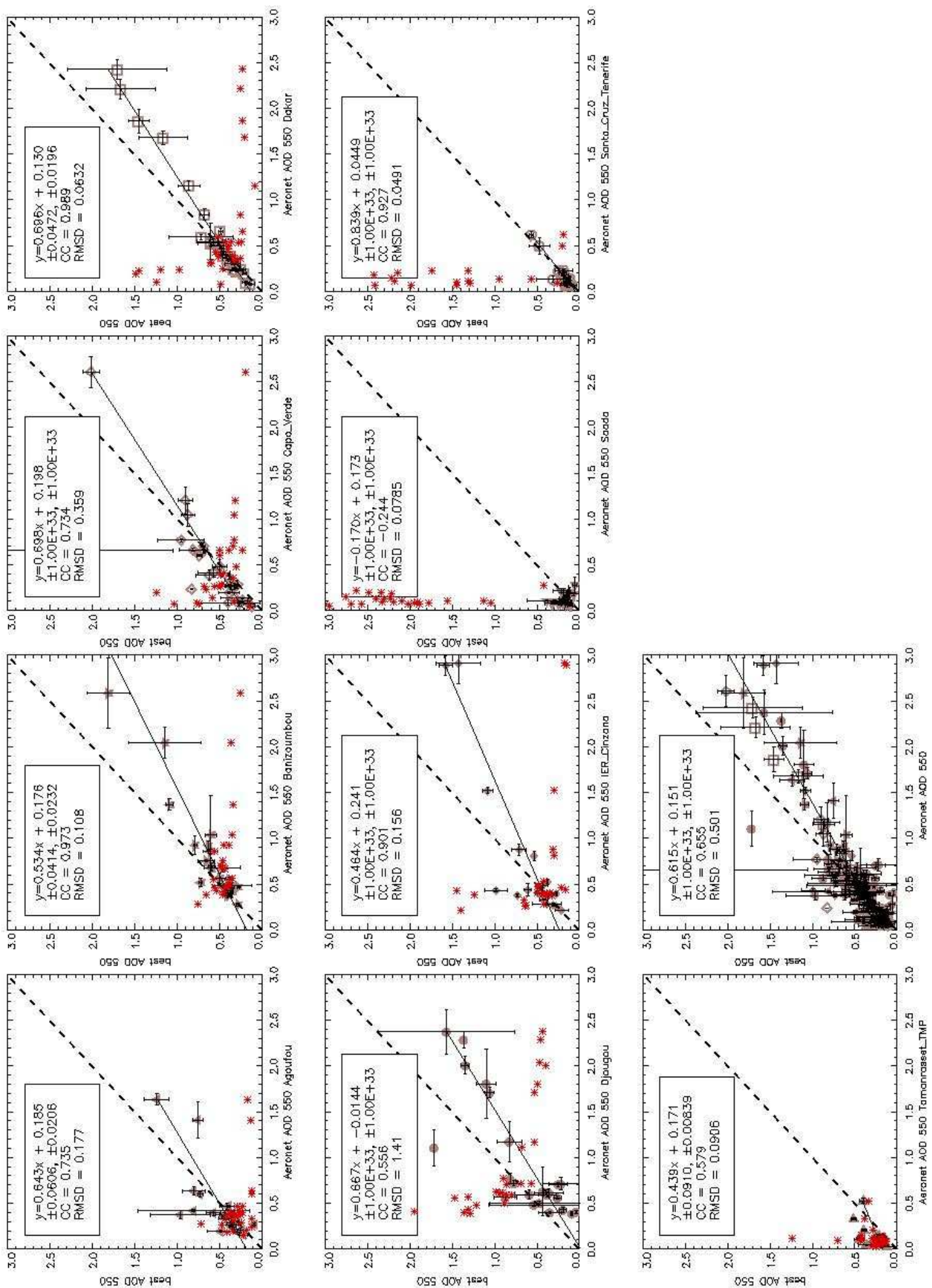

Fig. 12. Combined daily AOD vs. AERONET. Equivalent of Fig. 4 but obtained considering the combined AOD instead of a single satellite dataset. Different locations are shown in different plots and are represented by different symbols, as with Fig. 3. The red stars represent two times the AERONET Ångström coefficient (between 440 and $870 \mathrm{~nm}$ ). The final plots show all the coincidences. 
ocean and land, apart from OMI datasets, there is a tendency to underestimate the AOD, especially for high AOD (values more than 1) and low Ångström coefficients, conditions that are a good indication of dust. This can indicate that there is a need to improve dust optical properties and surface characterisation over land. Satellite retrievals in dust-dominated regions tend to overestimate instantaneous AOD in the low AOD range and underestimate it in the high range compared to AERONET (as already documented for MISR in Kahn et al., 2010). A greater diversity of dust optical models is needed to better represent different desert source regions, though other factors might also be involved.

A similar analysis has been performed with only the coincidences where AERONET Ångström coefficient is lower than 0.7 in order to test the satellite retrieval in dust conditions only. Apart from decreasing the numbers of coincidences (removing nearly all data in the Saada site), these results show little variation, less than $10 \%$ in correlation coefficient (CC) and root-mean-square differences (RMSD), and are not substantially different from Fig. 5.

A similar analysis has also been performed for the very dusty conditions (Ångström coeff. $<0.4$ and AOD $>0.5$ ) and clean conditions (Ångström coeff. $>0.70 .4$ and AOD $<0.5$ ). Table 4 summarises the AERONET comparisons in terms of number of coincidences, CC and bias with AERONET (where bias is the module mean difference between AERONET and satellite AOD), for the three cases: "all" coincidences (as data show in Fig. 5), "very dusty" condition and "clean" condition. Correlation coefficients are computed only for cases with more than five coincidences.

Some datasets specifically developed for dust (SEVIRIIR, SEVIRI-ORAC, MODIS) improve the CC between "all" and "very dusty" conditions, but the bias with AERONET increases. This could indicate that they can follow the dust storm better than all the other conditions, but not with the same accuracy. In all datasets, the bias increases in "very dusty" condition compared to "all" conditions, indicating that future work should be done to improve the retrieval in very dusty conditions. Results for "clean" conditions show obvious weakness in terms of CC for AATSR-SWA and SEVIRI-ORAC, but this was not the focus of this intercomparison. For example, SEVIRI-ORAC is only performed with the dust aerosol type which is not expected to represent well clean conditions. The datasets that give better results for all conditions are MISR, POLDER-OCEAN, and SEVIRI-IMP-VIS. Though note that the last two are ocean only datasets. MISR is possibly the dataset that performs best in all conditions (over ocean and land), but the limited coverage does not allow the quality under "very dusty" conditions to be tested in this study.

A comparison with AERONET is useful to assess the quality of the retrievals, but the quality control applied by AERONET limits the comparison to cloud-free conditions, and so the numerous cases in which the satellite retrievals are cloud contaminated are not assessed. Furthermore, note that
Table 5 does not distinguish between land and ocean/coastal sites which penalises datasets with more coverage over land.

\section{Satellite inter-comparison}

After the single datasets have applied their own quality control, for each day we compare, one by one, each dataset against the others. For every dataset, grid boxes with two or more measurements and standard deviation less than 0.5 have been considered. Figures 6 and 7 show examples for MISR over land and POLDER over ocean. The summary in terms of CC and RMSD is shown in Figs. 8 and 9.

The line over-plotted in the density plot is obtained with a linear fitting procedure, considering every latitude-longitude box mean AOD, and taking the related AOD STD as error. In the scatter plots, the values of CC, RMSD and best fit are also indicated. The comparison is performed separately for land and ocean.

In Figs. 8 and 9, the values above the diagonal refer to the comparison over land; the values below the diagonal refer to comparison over ocean. As expected, over ocean CCs are higher and RMSDs are lower.

AATSR and MISR are most correlated with each other, possibly because both exploit multi-angle viewing and because the local time of measurement differs only by half an hour. Figures 8 and 9 do not show any particular "time effect"; for example, if the difference in time of measurement plays a dominant role in this intercomparison, it would be expected that POLDER/OMI/AIRS (overpass at 13:30) would differ more from ATSR/MISR (overpass at 10:30) and they would agree better with each other, but this is not reflected in terms of CC and RMSD.

The comparisons with AERONET (Sect. 4) show better results than the satellite-to-satellite AOD inter-comparisons. This has been previously documented for MISR and MODIS (Mishchenko et al., 2007, 2010; Tanré, 2010). It is explained by considering AERONET AOD as ground truth. Each satellite AOD dataset has a confidence envelope spread around this "truth". When comparing any pair of satellite datasets directly, we cannot consider one as truth. For MISR and MODIS specifically, assumptions made in each algorithm mean that one instrument tends to overestimate AOD in specific situations where the other underestimates AOD. The result is that the satellite-AERONET envelope for each instrument is smaller than the envelope produced by comparing the two satellite instrument datasets directly; when the confidence envelopes are convolved correctly, the differences between MISR and MODIS are actually slightly smaller than might be expected from the individual instrument comparisons with AERONET (Kahn et al., 2009a). Nevertheless, the more likely reason why the comparisons with AERONET show better results than the satellite-to-satellite is presumably due to the fact that AERONET itself provides a stringent quality control and the resulting AERONET vs. satellite 

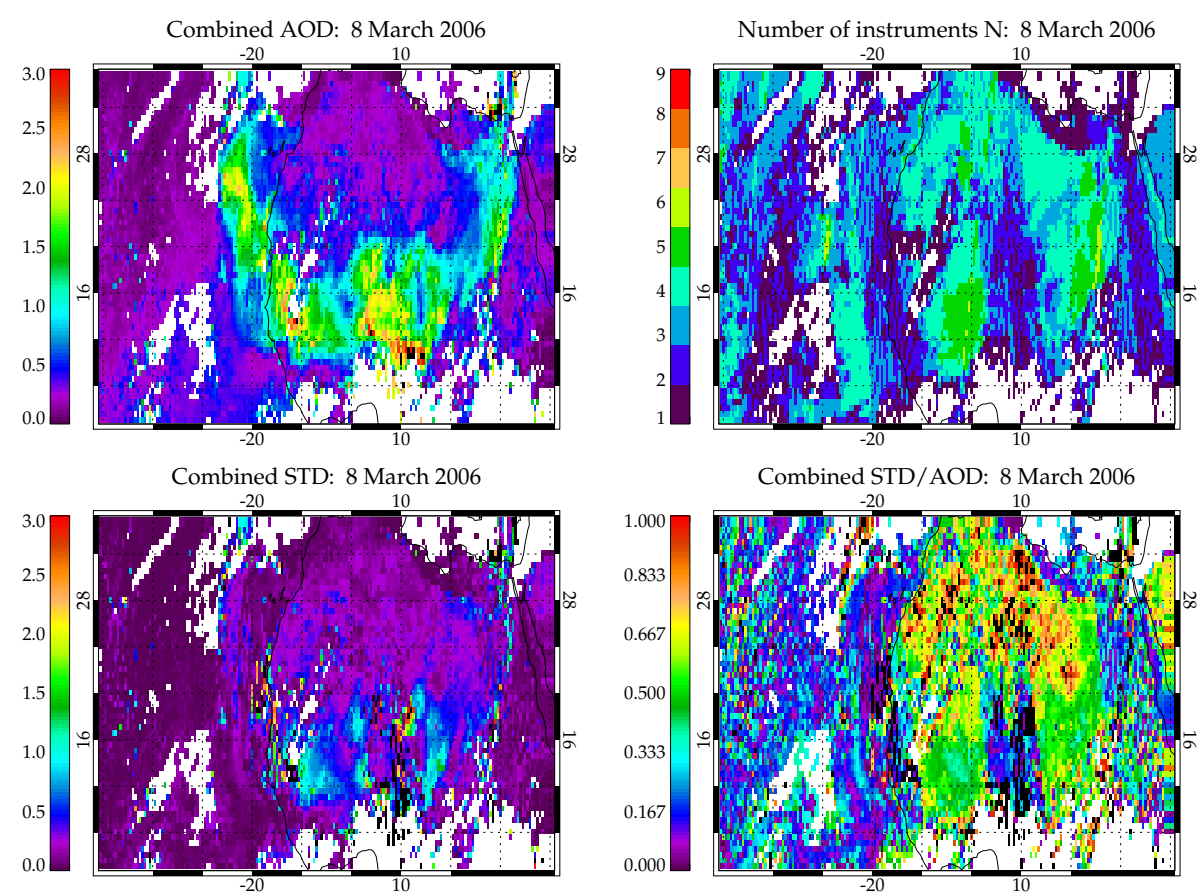

Fig. 13. Daily map for 8 March 2006 of the combined AOD (top left), the number $N$ of instruments considered for every box (top right), standard deviation STD (bottom left) and ratio between standard deviation and aerosol optical depth STD/AOD (bottom right).
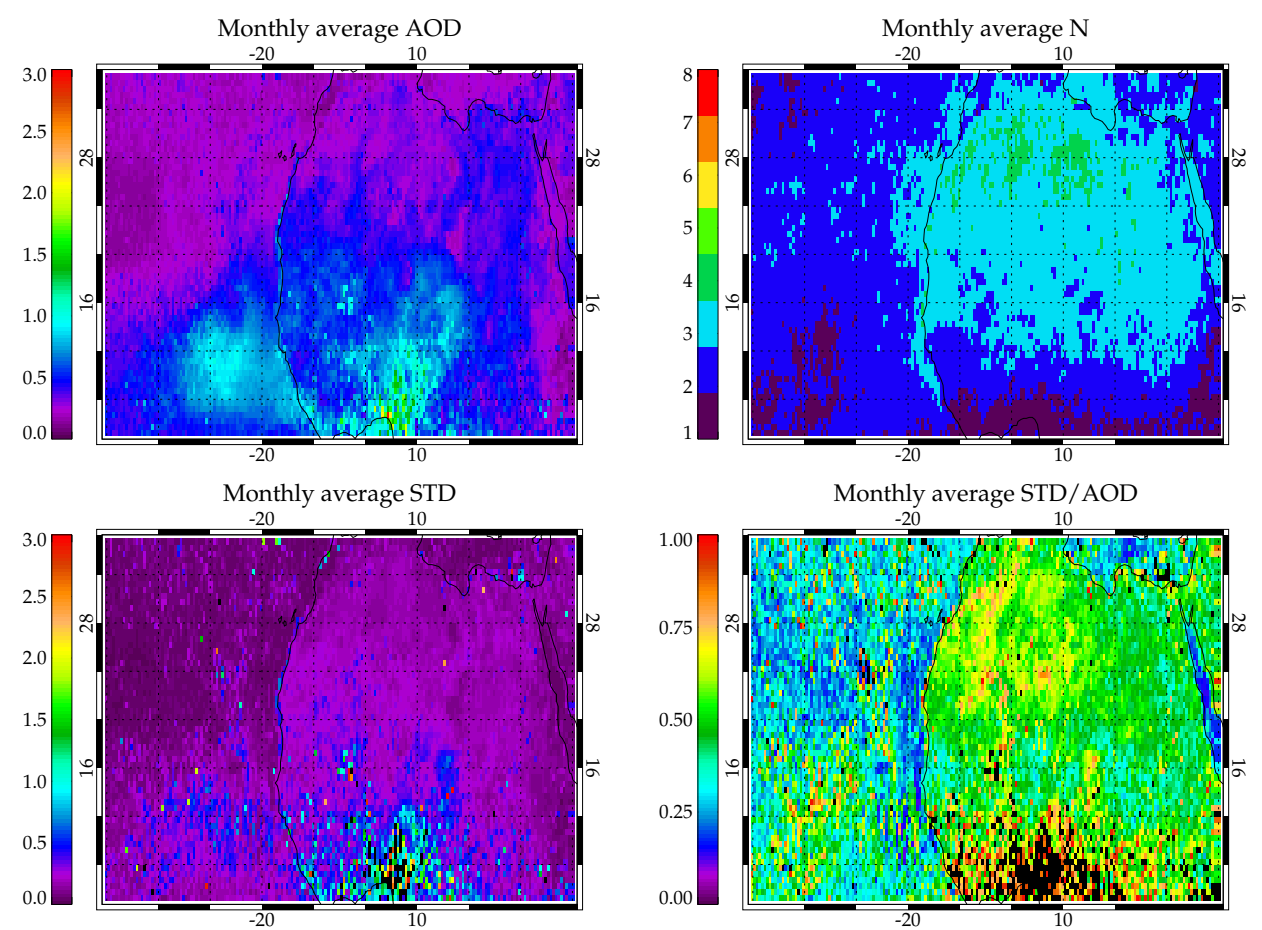

Fig. 14. Monthly average of AOD (top left), number $N$ of instruments considered (top right), standard deviation (bottom left) and ratio between standard deviation over AOD (bottom right). Values in black are higher than the maximum of the colour bar. 
comparisons are in cloud-free conditions, while the satellitesatellite results can be cloud contaminated.

\section{Combined dataset}

Because of the non-complete coverage of any single satellite dataset, it is helpful to follow the behaviour of dust plumes during March 2006 using a combination of all the different satellite datasets available. A combination weighted with error estimates would be the best way to characterise these dust events, but at present a complete quality assessment study for every dataset in every condition is not available.

In this work, a combined dataset is obtained using a simple average (as explained further below). It is used to analyse where there are the most discrepancies between datasets: this can be used to indicate which areas need improvement.

The average of all the datasets has been assimilated into the transport model SHAMAL to better understand dust transport (Banks et al., 2009; Banks 2010).

For each grid box and for each day of March, 2006, the satellite retrievals were averaged to create a daily mean "all retrievals" field. If the satellite instruments have more than one algorithm, the different algorithm results are averaged first for the same instrument, and then successively the average between the different instruments is performed. This is in order to avoid weighting more heavily an instrument with several datasets (for example, SEVIRI has four datasets in this comparison).

For each grid box, a daily average was calculated. Successively averaging these daily values gives monthly means. Figure 10 shows the daily average AOD obtained for March 2006. The daily average AOD from all datasets shows very good continuity, including at the coastal boundary and between areas with different numbers of datasets.

Fig. 11 shows the time evolution of the daily average AOD together with the values of all the datasets available, for two subregions selected as examples of dust plumes over ocean (between $11^{\circ}$ and $12^{\circ} \mathrm{N},-20^{\circ}$ and $-21^{\circ} \mathrm{E}$ ) and over land (between $15^{\circ}$ and $16^{\circ} \mathrm{N}, 5^{\circ}$ and $6^{\circ} \mathrm{E}$ ).

To check the quality of the combined dataset, a comparison with AERONET is produced in the same way as the individual dataset comparisons (e.g. Fig. 4). This is presented in Fig. 12. In this case, AERONET data are considered over a longer time interval, from 10:00 a.m. to 2:00 p.m., and, spatially, all the combined AODs that have the central grid box within $50 \mathrm{~km}$ of the AERONET site are considered (between one and four combined AODs are averaged in this comparison, depending on location). Values of CC and RMSD for the combined datasets are in the same range as the single dataset comparisons with AERONET. The error bars for single datasets are often larger in both axes, $\mathrm{x}$ and $y$, due to larger STD in satellite-combined AOD, and the larger variations in AERONET AOD inside the wider time interval. Once again, the best comparisons are obtained for coastal sites (Capo Verde, Dakar and Tenerife) and we notice an underestimation of AOD at high AOD and low Ångström coefficient.

Figure 13 shows the daily average AOD of all datasets for 8 March 2006, the numbers of instruments averaged in every box, STD and the ratio STD/AOD. The STD gives a measure of AOD differences between instruments: it can be seen as an uncertainty of AOD given by the difference in instruments, algorithms and aerosol models considered. The STD is generally, as expected, higher where the AOD is higher and in correspondence with the dust plume both over land and over ocean areas. It is not particularly related to the number of measurements used. The value of STD/AOD can be seen as relative error: when it is larger than 1 , it visualises where the spread between instrument values (STD) is higher than the AOD itself. Over ocean, the higher area corresponds to the plume itself and to pixels that may be affected by cloud contamination. Over land, the higher values occur where there is more likely to be uncertainty on surface characterisation (bright surface for the north of Africa) and again where there may be cloud contamination (the southeastern part of the plot). Some satellite cloud masks cannot distinguish water cloud from thick aerosol, so "cloudy conditions" for some retrievals might actually be dust.

Figure 14 presents the average over the month of all the images in Fig. 13.

Starting from the daily values, the averages over all the days have been computed in order to obtain the monthly values presented in Fig. 14. The plot of monthly STD shows the variation of AOD between datasets. As expected, it is related to the behaviour of AOD itself, and is higher where the AOD is higher. So in the monthly means, we have a higher dispersion of AOD values in the areas of higher average AOD conditions. The area in the bottom part of the plot over Africa (Nigeria approximately) is definitely an area overpassed by the March 2006 dust plume, but it is also where we have significant data screened out due to cloudy conditions (low values of $N$ in both monthly means and daily plots), so the large dispersion of AOD could be attributed to cloud.

The values of STD/AOD are shown in the spread of the data compared to the AOD itself, over the whole month. Looking at this plot together with the plot of $N$ (average number of dataset/measurements), it is possible to note that there are higher values where there are fewer measurements.

Over land, STD/AOD is larger than 1 in the region where we are presumably more affected by cloud contamination (southern part of the plot) and there is an area of consistently high values $(0.7-0.8)$ corresponding to a bright surface. Unfortunately, there is a lack of AERONET stations in this region.

Over ocean, the higher values are less localised and more "noisy" but surprisingly reach comparable values. 


\section{Conclusions}

This intercomparison has been valuable for identifying some deficiencies in retrieval schemes. For example, with SEVIRI ORAC the main issue is a bias over desert in clean conditions, which is attributed to error in the modelling of surface properties.

All datasets show a reasonably good agreement with AERONET. Typically, the standard deviation of observations with respect to AERONET is around 0.1-0.2. Discrepancies between satellite datasets are larger than this agreement with AERONET would imply. This is possibly due to the fact that AERONET itself provides a stringent quality control.

The standard deviation between datasets is higher in the desert dust plume and sometimes is comparable with the average AOD itself. However, the dispersion (standard deviation) of the AOD values between datasets compared with the average AOD itself (STD/AOD) presents higher values consistently, for the period considered, over the area of bright land surfaces. Unfortunately, over such regions there is a particular lack of AERONET stations.

The additional information (e.g. extending the spectral range used to UV or IR channels), which allows some datasets to work over bright surfaces, at the same time introduces problems due to variability of parameters that particularly affect these schemes (e.g. the dust optical model and surface properties). There is a need for improved dust optical properties and better characterisation of land surface properties over a broad spectral range. Comparisons should also be extended in the future to consider the aerosol models used in the different retrieval schemes.

There are remarkable differences in the spatial coverage of the daily products obtained with the individual satellite datasets, and this is due to differences in satellite coverage (overpass time, swath) and quality control data cuts (the last one is apparent from the plot of different datasets for the same instrument in Fig. 1). And, even if a pixel-by-pixel comparison has not been performed in this paper, the differences in spatial coverage have been found to make important contributions to the monthly mean differences.

Removal of data for quality control is one of the more important sources of such differences. For example, monthly means over ocean from the same satellite (but different datasets/algorithm) still show discrepancies. To a lesser extent, differences are also produced by differences in aerosol model and retrieval algorithm used. With the intention of avoiding clouds, some datasets make very restrictive data cuts and cut the densest parts of the plume, which leads to a large bias in the monthly mean.

Every single dataset has some weakness due to the single instrument characteristic and to the algorithm itself, but the combined AOD from all datasets for March 2006 shows very good spatial continuity, in particular over the coastline and over boundaries where the number of contributing datasets changes.
This encouraging result from such a simple method suggests that the best way to characterise an aerosol event is to exploit the complementary capacities of different sensors. The development of more optimal techniques to perform this merging could be an interesting topic for further research.

All the datasets used in this comparison are available at: ftp://ftp.atm.ox.ac.uk/pub/user/elisa/DRI/.

Acknowledgements. University of Oxford authors acknowledge support from the National Centre of Earth Observation. Ben Veihelmann's contribution to this paper was supported by the Netherlands Space Office (NSO). The OMI instrument was contributed by the Netherlands (NSO/KNMI) and Finland (TEKES/FMI) to the NASA EOS-Aura mission. We thank the PI investigators (Philippe Goloub, Didier Tanré, Bernadette Chatenet, Bernard Mougenot, Benoit Duchemin, Emilio Cuevas, Juan Cuesta) and their staff for establishing and maintaining the Agoufou, Banizoumbou, Capo Verde, Dakar, Djougou, IER Cinzana, Saada, Santa Cruz Tenerife, Tamanrasset AERONET sites used in this investigation.

Edited by: G. Pappalardo

\section{References}

Acarreta, J. R. and de Haan, J. F.: Cloud pressure algorithm based on $\mathrm{O} 2-\mathrm{O} 2$ absorption, in: OMI algorithm theoretical basis document volume III: clouds, aerosols, and surface UV irradiance, edited by: Stammes, P., v2.0 Edn., ATBD-OMI-03, 2002.

Acarreta, J. R., de Haan, J. F., and Stammes, P.: Cloud pressure retrieval using the $\mathrm{O} 2-\mathrm{O} 2$ absorption band at $477 \mathrm{~nm}$, J. Geophys. Res., 109, D05204, doi:10.1029/2003JD003915, 2004.

Antoine, D. and Morel, A.: A multiple scattering algorithm for atmospheric correction of remotely-sensed ocean colour (MERIS instrument) : principle and implementation for atmospheres carrying various aerosols including absorbing ones, Int. J. Remote Sens., 20, 1875-1916, 1999.

Antoine, D. and Nobileau, D.: Recent increase of Saharan dust transport over the Mediterranean Sea, as revealed from ocean color satellite (SeaWiFS) observations, J. Geophys. Res. Atmos., 111, D12214, doi:10.1029/2005JD006795, 2006.

Aumann, H. H., Chahine, M. T., Gautier, C., Goldberg, M., Kalnay, E., McMillin, L., Revercomb, H., Rosenkranz, P. W., Smith, W. L., Staelin, D., Strow, L., and Susskind, J.: AIRS/AMSU/HSB on the Aqua mission: Design, science objectives, data products and processing systems, IEEE T. Geosci. Remote Sens., 41, 253-264, 2003.

Banks, J. R.: The Emission and Transport of Saharan Dust, PhD Thesis, University of Oxford, 2010.

Banks, J. R., Carboni, E., Grainger, R. G., Juckes, M. N., and Laurent, B.: Modelling the Emission and Transport of Saharan Dust- the SHAMAL model, 3rd International AMMA conference, Ouagadougou, Burkina Faso, 20-24 July 2009.

Bevan, S. L., North, P. R. J., Grey, W. M. F., Los, S. O., and Plummer, S. E.: The impact of atmospheric aerosol from biomass burning on Amazon dry-season drought, J. Geophys. Res., 114, D09204, doi:10.1029/2008JD011112, 2009.

Bevan, S. L., North, P. R. J., Los, S. O., and Grey, W. M. F.: A global dataset of atmospheric aerosol optical depth and surface 
reflectance from AATSR, Remote Sens. Environ., 116, 199-210, 2012.

Birks, A.: Improvements to the AATSR IPF relating to land surface temperature, European Space Agency Technical Note, 2004.

Brindley, H. and Ignatov, A.: Retrieval of mineral aerosol optical depth and size information from Meteosat second generation SEVIRI solar reflectance bands, Remote Sens. Environ., 102, 344363, 2006.

Brindley, H. and Russell, J.: Improving GERB scene identification using SEVIRI: Infrared dust detection strategy, Remote Sens. Environ., 104, 426-446, 2006.

Brindley, H. and Russell, J.: An assessment of Saharan dust loading and the corresponding cloud-free longwave direct radiative effect from geostationary satellite observations, J. Geophys. Res., 114, D23201, doi:10.1029/2008JD011635, 2009.

Bulgin, C., Palmer, P. I., Merchant, C. J., Siddans, R., Gonzi, S., Poulsen, C. A., Thomas, G. E., Sayer, A. M., Carboni, E., Grainger, R. G., Highwood, E. J., and Ryder, C. L.: Quantifying the response of the ORAC aerosol optical depth retrieval for MSG SEVIRI to aerosol model assumptions, J. Geophys. Res. 116, D05208, doi:10.1029/2010JD014483, 2011.

Carboni, E., Thomas, G., Grainger, R. G., Poulsen, C., Siddans, R., Peters, D., Campmany, E., Sayer, A., and Brindley, H.: Retrieval of aerosol properties from SEVIRI using visible and infrared channels, Proceedings of EUMETSAT/AMS conference 2007, Amsterdam, 24-28 September, 2007.

Chen, W.-T., Kahn, R., Nelson, D., Yau, K., and Seinfeld, J.: Sensitivity of multi-angle imaging to optical and microphysical properties of biomass burning aerosols, J. Geophys. Res., 113, D10203, doi:10.1029/2007JD009414, 2008.

Chou, M.-D., Lee, K.-T., Tsay, S.-C., and Fu, Q.: Parameterization for cloud longwave scattering for use in Atmospheric Models, J. Climate, 12, 159-169, 1999.

Christopher, S. A., Gupta, P., and Haywood, J.: Aerosol optical thicknesses over North Africa: 1. Development of a product for model validation using Ozone Monitoring Instrument, Multiangle Imaging Spectroradiometer, and Aerosol Robotic Network, J. Geophys. Res.-Atmos., 113, D00C04, doi:10.1029/2007JD009446, 2008.

Christopher, S. A.,Johnson, B., Jones, T. A., and Haywood, J.: Vertical and spatial distribution of dust from aircraft and satellite measurements during the GERBILS field campaign, Geophys. Res. Lett., 36, L06806, doi:10.1029/2008GL037033, 2009.

Christopher, S., Gupta, P., Johnson, B. B., Ansell, C., Brindley, H., and Haywood, J.: Multi-sensor satellite remote sensing of dust aerosols over North Africa during GERBILS, Q. J. Roy. Meteorol. Soc., 137, 1168-1178, doi:10.1002/qj.863, 2011.

Curier, R. L., Veefkind, J. P., Braak, R., Veihelmann, B., Torres, O., and de Leeuw, G.: Retrieval of aerosol optical properties from OMI radiances using a multiwavelength algorithm: Application to western Europe, J. Geophys. Res., 113, D17S90, doi:10.1029/2007JD008738, 2008.

Davies, W. H., North, P. R. J., Grey, W. M. F., and Barnsley, M. J.: Improvements in aerosol optical depth estimation using multiangle CHRIS/PROBA images, IEEE T. Geosci. Remote, 48, 18-24, 2010.

De Haan, J. F., Bosma, P. B., and Hovenier, J. W.: The adding method for multiple scattering calculations of polarized light, Astron. Astrophys., 183, 371-391, 1987.
Deschamps, P.-Y., Bréon, F.-M., Leroy, M., Podaire, A., Bricaud, A., Buriez, J.-C., and Sèze, G.: The POLDER mission: Instrument characteristics and scientific objectives, IEEE T. Geosci. Remote, 32, 598-615, 1994.

De Paepe, B., Ignatov, A., Dewitte, S., and Ipe, A.: Aerosol retrieval over ocean from SEVIRI for the use in GERB Earth's radiation budget analysis, Remote Sens. Environ., 112, 2455-2468, 2008.

De Souza-Machado, S., Strow, L., Motteler, H. E., and Hannon, S. E.: Infrared dust spectral signatures from AIRS, Geophys. Res. Lett., 33, L03801, doi:10.1029/2005GL024364, 2006.

De Souza-Machado, S. G., Strow, L. L., Imbiriba, B., McCann, K. Hoff, R. M., Hannon, S. E., Martins, J. V., Tanré, D., Deuzé, J. L., Ducos, F., and Torres, O.: Infrared retrievals of dust using AIRS: Comparisons of optical depths and heights derived for a North African dust storm to other collocated EOS ATrain and surface observations, J. Geophys. Res., 115, D15201, doi:10.1029/2009JD012842, 2010.

Derrien, M. and Le Gleau, H.: MSG/SEVIRI cloud mask and type from SAFNWC, Int. J. Remote Sens., 26, 4707-4732, doi:10.1080/01431160500166128, 2005.

Deuzé, J. L., Bréon, F. M., Devaux, C., Goloub, P., Herman, M., Lafrance, B., Maignan, F., Marchand, A., Perry, G., and Tanré, D.: Remote sensing of aerosols over land surfaces from POLDER-ADEOS-1 polarized measurements, J. Geophys. Res.Atmos., 106, 4913-4926, 2001.

Diner, D. J., Beckert, J. C., Reilly, T. H., Bruegge, C. J., Conel, J. E., Kahn, R., Martonchik, J. V., Ackerman, T. P., Davies, R., Gerstl, S. A. W., Gordon, H. R., Muller, J.-P., Myneni, R., Sellers, R. J., Pinty, B., and Verstraete, M. M.: Multiangle Imaging SpectroRadiometer (MISR) description and experiment overview, IEEE T. Geosci. Remote, 36, 1072-1087, 1998.

Dubovik, O., Sinyuk, A., Lapyonok, T., Holben, B., Brent, N., Mishchenko, M., Yang, P., Eck, T. F., Volten, H., Munoz, O., Veihelmann, B., van der Zande, W. J., Leon, J.-F., Sorokin, M., and Slutsker, I.: Application of spheroid models to account for aerosol particle nonsphericity in remote sensing of desert dust, J. Geophys. Res.-Atmos., 111, D11208, doi:10.1029/2005JD006619, 2006

ESTEC - Validation of the MERIS land data products: Validation of the aerosol level 3 product, Final Report ESTEC Contract 16837/02/NL/FF, 2006.

EUMETSAT - Cloud detection for MSG-Algorithm theoretical basis document, EUM/MET/REP/0132, 2007.

Ginoux, P., Chin, M., Tegen, I., Prospero, J., Holben, B., Dubovik, O., and Lin, S.-J.: Sources and global distributions of dust aerosols simulated with the GOCART model, J. Geophys. Res., 106, 20255-20273, doi:10.1029/2000JD000053, 2001.

Gordon, H. R. and Wang, M.: Retrieval of water-leaving reflectance and aerosol optical thickness over the oceans with SeaWiFS: a priliminary algorithm, Appl. Opt., 33, 443-452, 1994.

Grey, W. M. F. and North, P. R. J.: Satellite aerosol remote sensing over land. chapter Aerosol optical depth from dual-view (A)ATSR satellite observations, Praxis Publishing Ltd., Chichester, UK, Springer, 2009.

Grey, W. M. F., North, P. R. J., and Los, S. O.: Computationally efficient method for retrieving aerosol optical depth from ATSR2 and AATSR data, Appl. Opt., 45, 2786-2795, 2006 a.

Grey, W. M. F., North, P. R. J., Los, S. O., and Mitchell, R. M.: Aerosol optical depth and land surface reflectance from 
multiangle AATSR measurements: Global validation and intersensor comparisons, IEEE T. Geosci. Remote, 44, 2184-2197, $2006 b$.

Herman, M., Deuze, J. L., Marchand, A., Roger, B., and Lallart, P.: Aerosol remote sensing from POLDER/ADEOS over the ocean: Improved retrieval using a nonspherical particle model, J. Geophys. Res.-Atmos., 110, D10S02, doi:10.1029/2004JD004798, 2005.

Hess, M., Koepke, P., and Schult, I.: Optical Properties of Aerosols and Clouds: The software package OPAC, B. Am. Meteorol. Soc., 79, 831-844, 1998.

Holben, B. N., Eck, T. F., Slutsker, I., Tanré, D., Buis, J. B., Seltzer, A., Vermote, E., Reagan, J. A., Kaufman, J. A., Nakajima, T., Lavenu, F., Jankowiak, I., and Smirnov, A.: AERONET - A federated Instrument Network and Data Archive for Aerosol Characterization, Remote Sens. Environ., 66, 1-16, 1998.

Hsu, N. C., Tsay, S.-C., King, M. D., and Herman, J. R.: Aerosol properties over bright-reflecting source regions, IEEE T. Geosci. Remote, 42, 557-569, 2004.

Hsu, N. C., Tsay, S.-C., King, M. D., and Herman, J. R.: Deep Blue retrievals of Asian aerosol properties during ACE-Asia, IEEE T. Geosci. Remote, 44, 3180-3195, 2006.

Ichoku, C., Chu, D. A., Mattoo, S., Kaufman, Y. J., Remer, L. A., Tanre, D., Slutsker, I., and Holben, B. N.: A spatio-temporal approach for global validation and analysis of MODIS aerosol products, Geophys. Res. Lett., 29, 8006, doi:10.1029/2001GL013206, 2002.

Ignatov, A. and Stowe, L.: Aerosol retrievals from individual AVHRR channels. Part I: Retrieval algorithm and transition from Dave to $6 \mathrm{~S}$ radiative transfer model, J. Atmos. Sci., 59, 313-334, 2002.

Ipe, A., Bertrand, C., Clerbaux, N., Dewitte, S., and Gonzalez, L.: Validation and homogenization of cloud optical depth and cloud fraction retrievals for GERB/SEVIRI scene identification using Meteosat-7 data, Atmos. Res., 72, 17-37, 2004.

Jickells, T. D., An, Z. S., Andersen, K. K., Baker, A. R., Bergametti, G., Brooks, N., Cao, J. J., Boyd, P. W., Duce, R. A., Hunter, K. A., Kawahata, H., Kubilay, N., laRoche, J., Liss, P. S., Mahowald, N., Prospero, J. M., Ridgwell, A. J., Tegen, I., and Torres, R.: Global Iron Connections Between Desert Dust, Ocean Biogeochemistry, and Climate Science, 308, 67, doi:10.1126/science.1105959, 2005.

Kahn, R. A., Nelson, D. L., Garay, M., Levy, R. C., Bull, M. A., Martonchik, J. V., Diner, D. J., Paradise, S. R., Hansen, E. G., and Remer, L. A.: MISR Aerosol product attributes, and statistical comparison with MODIS, IEEE T. Geosci. Remote, 47, 40954114, 2009a.

Kahn, R., Petzold, A., Wendisch, M., Bierwirth, E., Dinter, T., Esselborn, M., Fiebig, M., Heese, B., Knippertz, P., Muller, D., Schladitz, A., and Von Hoyningen-Huene, W.: Desert Dust Aerosol Air Mass Mapping in the western Sahara, Using particle properties derived from space-based multi-angle imaging, Tellus, 61, 239-251, 2009b.

Kahn, R. A., Gaitley, B. J., Garay, M. J., Diner, D. J., Eck, T., Smirnov, A., and Holben, B. N.: Multiangle Imaging SpectroRadiometer global aerosol product assessment by comparison with the Aerosol Robotic Network, J. Geophys. Res., 115, D23209, doi:10.1029/2010JD014601, 2010.
Kahn, R. A., Garay, M. J., Nelson, D. L., Levy, R. C., Bull, M. A., Diner, D. J., Martonchik, J. V., Hansen, E. G., Remer, L. A., and Tanré, D.: Response to Toward unified satellite climatology of aerosol properties. 3. MODIS versus MISR versus AERONET?, J. Quant. Spectrosc. Ra., 112, 901-909, doi:10.1016/j.jqsrt.2009.11.003, 2011.

Kalashnikova, O. V. and Kahn, R.: Ability of multiangle remote sensing observations to identify and distinguish mineral dust types: Part 2. Sensitivity over dark water, J. Geophys. Res., 111, D11207, doi:10.1029/2005JD006756, 2006.

Kalashnikova, O. V. and Sokolik, I. N.: Importance of shapes and compositions of wind-blown dust particles for remote sensing at solar wavelengths, Geophys. Res. Lett., 29, 1398, doi:10.1029/2002GL014947, 2002.

Kalashnikova, O. V., Kahn, R., Sokolik, I. N., and Li, W.-H.: The ability of multi-angle remote sensing observations to identify and distinguish mineral dust types: Part 1. Optical models and retrievals of optically thick plumes, J. Geophys. Res., 110, D18S14, doi:10.1029/2004JD004550, 2005.

Kandler, K., Benker, N., Bundke, U., Cuevas, E., Ebert, M., Knippertz, P., Rodriguez, S., Schuetz, L., and Weinbruch, S.: Chemical composition and complex refractive index of Saharan Mineral Dust at Izana, Tenerife (Spain) derived by electron microscopy, Atmos. Environ., 41, 8058-8074, 2007.

Kaufman, Y. J., Tanré, D., Remer, L. A., Vermote, E. F., Chu, A., and Holben, B. N.: Operational remote sensing of tropospheric aerosol over land from EOS moderate resolution imaging spectroradiometer, J. Geophys. Res., 102, 17051-17067, doi:10.1029/96JD03988, 1997.

Kaufman, Y. J., Smirnov, A., Holben, B. N., and Dubovik, O.: Baseline maritime aerosol: methodology to derive the optical thickness and scattering properties, Geophys. Res. Lett., 28, 3251-3254, 2001.

Kokhanovsky, A. A., Breon, F.-M., Cacciari, A., Carboni, E., Diner, D., Di Nicolantonio, W., Grainger, R. G., Grey, W. M. F., Höller, R., Lee, K.-H., Li, Z., North, P. R. J., Sayer, A., Thomas, G., and von Hoyningen-Huene, W.: Aerosol remote sensing over land: a comparison of satellite retrievals using different algorithms and instruments, Atmos. Res., 85, 372-394, doi:10.1016/j.atmosres.2007.02.008, 2007.

Kokhanovsky, A. A., Deuzé, J. L., Diner, D. J., Dubovik, O., Ducos, F., Emde, C., Garay, M. J., Grainger, R. G., Heckel, A., Herman, M., Katsev, I. L., Keller, J., Levy, R., North, P. R. J., Prikhach, A. S., Rozanov, V. V., Sayer, A. M., Ota, Y., Tanré, D., Thomas, G. E., and Zege, E. P.: The inter-comparison of major satellite aerosol retrieval algorithms using simulated intensity and polarization characteristics of reflected light, Atmos. Meas. Tech., 3, 909-932, doi:10.5194/amt-3-909-2010, 2010.

Koven, C. D. and Fung, I.: Identifying global dust source areas using high-resolution land surface form, J. Geophys. Res., 113, D22204, doi:10.1029/2008JD010195, 2008.

Lean, K.: Empirical methods for detecting atmospheric aerosol events from satellite measurements, MPhys project report, University of Oxford, available at: http://www.atm.ox.ac.uk/group/ eodg/mphys_reports/2009_Lean.pdf (last access: August 2012), 2009.

Legrand, M., Plana-Fattori, A., and N'doume, C.: Satellite detection of dust using the IR imagery of Meteosat 1 . Infrared difference dust index, J. Geophys. Res., 106, 18251-18274, 2001. 
Levy, R. C., Leptoukh, G. G., Kahn, R., Zubko, V., Gopalan, A., and Remer, L. A.: A critical look at deriving monthly aerosol optical depth from satellite data, IEEE T. Geosci. Remote, 47, 2942-2956, doi:10.1109/TGRS.2009.2013842, 2009.

Martonchik, J. V., Diner, D. J., Kahn, R., Gaitley, B., and Holben, B.: Comparison MISR and AERONET aerosol optical depth over desert sites, Geophys. Res. Lett., 31, L16102, doi:10.1029/2004GL019807, 2004.

Martonchik, J. V., Kahn, R. A., and Diner, D. J.: Retrieval of Aerosol Properties over Land Using MISR Observations, in: Satellite Aerosol Remote Sensing Over Land, edited by: Kokhanovsky, A., Springer, Berlin, 2009.

MeteoFrance: User manual for the PGE01-02-03 of the SAFNWC/MSG: Scientific part, Report SAF/NWC/IOP/MFL/SCI/SUM/01, 65 pp., Paris, 2005.

Mishchenko, M. I. and Travis, L. D.: Capabilities and limitations of a current FORTRAN implementation of the T-matrix method for randomly oriented, rotationally symmetric scatterers, J. Quant. Spectrosc. Ra., 60, 309-324, doi:10.1016/S00224073(98)00008-9, 1998.

Mishchenko, M. I., Travis, L. D., Kahn, R. A., and West, R. A.: Modeling phase functions for dustlike tropospheric aerosols using a shape mixture of randomly oriented polydisperse spheroids, J. Geophys. Res.-Atmos., 102, 16831-16847, doi:10.1029/96JD02110, 1997.

Mishchenko, M. I., Geogdzhayev, I. V., Liu, L., Ogren, J. A., Lacis, A. A., Rossow, W. B., Hovenier, J. W., Volten, H., and Munoz, O.: Aerosol retrievals from AVHRR radiances: effects of particle nonsphericity and absorption and an updated long-term global climatology of aerosol properties, J. Quant. Spectrosc. Ra., 7980, 953-972, 2003.

Mishchenko, M. I., Geogdzhayev, I. V., Cairns, B., Carlson, B. E., Chowdhary, J., Lacis, A. A., Liu, L., Rossow, W. B., and Travis, L. D.: Past, present, and future of global aerosol climatologies derived from satellite observations: A perspective, J. Quant. Spectrosc. Ra., 106, 325-347, doi:10.1016/j.jqsrt.2007.01.007, 2007.

Mishchenko, M. I., Liu, L., Geogdzhayev, I. V., Travis, L. D., Cairns, B., and Lacis, A. A.: Toward unified satellite climatology of aerosol properties. 3. MODIS versus MISR versus AERONET, J. Quant. Spectrosc. Ra., 111, 540-552, 2010.

Moulin, C., Gordon, H. R., Banzon, V. F., and Evans, R. H.: Assessment of Saharan dust absorption in the visible from SeaWiFS imagery, J. Geophys. Res., 106, 18239-18249, 2001.

Myhre, G., Stordal, F., Johnsrud, M., Diner, D. J., Geogdzhayev, I. V., Haywood, J. M., Holben, B. N., Holzer-Popp, T., Ignatov, A., Kahn, R. A., Kaufman, Y. J., Loeb, N., Martonchik, J. V., Mishchenko, M. I., Nalli, N. R., Remer, L. A., SchroedterHomscheidt, M., Tanré, D., Torres, O., and Wang, M.: Intercomparison of satellite retrieved aerosol optical depth over ocean during the period September 1997 to December 2000, Atmos. Chem. Phys., 5, 1697-1719, doi:10.5194/acp-5-1697-2005, 2005.

Nadal, F. and Bréon, F. M.: Parameterization of surface polarised reflectance derived from POLDER spaceborne measurements, IEEE T. Geosci. Remote, 37, 1709-1718, 1999.

Nobileau, D. and Antoine, D.: Detection of blue-absorbing aerosols using nearinfrared and visible (ocean color) remote sensing observations, Remote Sens. Environ., 95, 368-387, 2005.
North, P. R. J.: Estimation of aerosol opacity and land surface bidirectional reflectance from ATSR-2 dual-angle imagery: Operational method and validation, J. Geophys. Res., 107, 4149, doi:10.1029/2000JD000207, 2002.

North, P. R. J., Briggs, S. A., Plummer, S. E., and Settle, J. J.: Retrieval of land surface bidirectional reflectance and aerosol opacity from ATSR-2 multiangle imagery, IEEE T. Geosci. Remote, 37, 526-537, 1999.

Plummer, S. E.: The Globcarbon cloud detection system for the along-track scanning radiometer (ATSR) sensor series, IEEE T. Geosci. Remote, 46, 1718-1727, 2008.

Sayer, A. M., Thomas, G. E., and Grainger, R. G.: A sea surface reflectance model for (A)ATSR, and application to aerosol retrievals, Atmos. Meas. Tech., 3, 813-838, doi:10.5194/amt-3813-2010, 2010a.

Sayer, A. M., Thomas, G. E., Palmer, P. I., and Grainger, R. G.: Some implications of sampling choices on comparisons between satellite and model aerosol optical depth fields, Atmos. Chem. Phys., 10, 10705-10716, doi:10.5194/acp-10-107052010, 2010b.

Sayer, A. M., Thomas, G. E., Grainger, R. G., Carboni, E., Poulsen, C., and Siddans, R.: Use of MODIS-derived surface reflectance data in the ORAC-AATSR aerosol retrieval algorithm: impact of differences between sensor spectral response functions, Remote Sens. Environ., 116, 177-188, 2012.

Schaaf, C. B., Gao, F., Strahler, A. H., Lucht, W., Li, X., Tsang, T., Strugnell, N. C., Zhang, X., Jin, Y., Mulle, J.-P., Lewis, P., Barnsley, M., Hobson, P., Disney, M., Roberts, G., Dunderdale, M., Doll, C., D'Entremont, R., Hu, B., Liang, S., Privette, J. L., and Roy, D. P.: First Operational BRDF, Albedo and Nadir Reflectance Products from MODIS, Remote Sens. Environ., 83, 135-148, 2002.

Shettle, E. P. and Fenn, R. W.: Models for the aerosols of the lower atmosphere and the effects of humidity variations on their optical properties, Environmental Research Papers, No. 676, AFGL-TR79-0214, Air Force Geophysics Laboratory, 20 September, 1979.

Smirnov, A., Holben, B. N., Eck, T. F., Dubovik, O., and Slutsker, I.: Cloud-screening and quality control algorithms for the AERONET database, Remote Sens. Environ., 73, 337-349, 2000.

Sneep, M., de Haan, J. F., Stammes, P., Wang, P., Vanbauce, C., Joiner, J., Vasilkov, A. P, and Levelt, P. F.: Three way comparison between OMI and PARASOL cloud pressure products, J. Geophys. Res., 113, D15S23, doi:10.1029/2007JD008694, 2008.

Stammes, P.: Spectral modelling in the UV-visible range, in: IRS2000: Current problems in atmospheric radiation, edited by: Smith, W. L. and Timofeyev, Y. M., A. Deepak Publishing, Hampton (Va), 2001.

Stammes, P., de Haan, J., and Hovenier, J.: The polarized internal radiation field of a planetary atmosphere, Astron. Astrophys., 225, 239-259, 1989.

Tanré, D.: Derivation of tropospheric aerosol properties from satellite observations, C. R. Geosci., 342, 403-411, 2010.

Tanré, D., Bréon, F. M., Deuzé, J. L., Herman, M., Goloub, P., Nadal, F., and Marchand, A.: Global observation of anthropogenic aerosols from satellite, Geophys. Res. Lett., 28, 45554558, 2001.

Thomas, G. E., Carboni, E., Sayer, A. M., Poulsen, C. A., Siddans, R., and Grainger, R. G.: Oxford-RAL Aerosol and Cloud 
(ORAC): aerosol retrievals from satellite radiometers in Satellite Aerosol Remote Sensing Over Land, edited by: Kokhanovsky, A. A. and de Leeuw, G., Springer, 2009.

Torres, O., Bhartia, P. K., Herman, J. R., Ahmad, Z., and Gleason, J.: Derivation of aerosol properties from satellite measurements of backscattered ultraviolet radiation; Theoretical basis, J. Geophys. Res., 103, 17099-17110, 1998.

Torres, O., Decae, R., Veefkind, J. P., and De Leeuw, G.: OMI aerosol retrieval algorithm, in: OMI algorithm theoretical basis document volume III: clouds, aerosols, and surface UV irradiance, edited by: Stammes, P., v2.0 Ed., ATBD-OMI-03, 2002.

Torres, O., Bhartia, P. K., Sinyuk, A., Welton, E. J., and Holben, B.: Total Ozone Mapping Spectrometer measurements of aerosol absorption from space: comparison to SAFARI 2000 groud-based observations, J. Geophys. Res., 110, D10S18, doi:10.1029/2004JD004611, 2005.

Torres, O., Tanskanen, A., Veihelmann, B., Ahn, C., Braak, R., Bhartia, P. K., Veefkind, P., and Levelt, P.: Aerosols and surface UV products from Ozone Monitoring Instrument observations: An overview, J. Geophys. Res., 112, D24S47, doi:10.1029/2007JD008809, 2007.

World Climate Research Program (WCRP): A preliminary cloudless standard atmosphere for radiation computation, International Association for Meteorology and Atmospheric Physics, Radiation Commission, Boulder, CO, USA, 1984, WCP-112, WMO/TD-No., 24 March 1986, 60 pp., 1986.
Veefkind, J. P. and De Leeuw, G.: A new algorithm to determine the spectral aerosol optical depth from satellite radiometer measurements, J. Aerosol Sci., 29, 1237-1248, 1998.

Veihelmann, B., Levelt, P. F., Stammes, P., and Veefkind, J. P.: Simulation study of the aerosol information content in OMI spectral reflectance measurements, Atmos. Chem. Phys., 7, 3115-3127, doi:10.5194/acp-7-3115-2007, 2007.

Vermote, E. F., Tanre, D., Deuze, J. L., Herman, M., and Morcrette, J.-J.: Second simulation of the satellite signal in the solar spectrum, 6S: An overview, IEEE T. Geosci. Remote, 35, 675-686, 1997.

Volz, F. E.: Infrared optical constants of ammonium sulfate, Sahara dust, volcanic pumice and flyash, Appl. Opt., 12, 564-568, 1973.

Xia, X. and Zong, X.: Shortwave versus longwave direct radiative forcing by Taklimakan dust aerosols, Geophys. Res. Lett., 36, L07803, doi:10.1029/2009GL037237, 2009.

Xia, X. G., Wang, P. C., and Wang, Y. S.: Aerosol optical depth over the Tibetan Plateau and its relation to aerosols over the Taklimakan Desert, Geophys. Res. Lett., 35, L16804, doi:10.1029/2008GL034981, 2008. 